\title{
Advanced Transition Preemption Strategy for Signalized Intersections near Highway-Rail Grade Crossings with Dual Tracks
}

\author{
Yifeng Chen ${ }^{(D)},{ }^{1}$ Laurence R. Rilett $\mathbb{D D}^{2}$ and Zifeng Wu $\mathbb{D}^{3}$ \\ ${ }^{1}$ AECOM, Southfield, MI 48034, USA \\ ${ }^{2}$ Auburn University Transportation Research Institute, Auburn University, Auburn, AL 36849, USA \\ ${ }^{3}$ Kittelson \& Associates, Oakland, CA 94612, USA \\ Correspondence should be addressed to Yifeng Chen; yfchen@huskers.unl.edu
}

Received 27 December 2020; Accepted 30 October 2021; Published 8 March 2022

Academic Editor: Kun An

Copyright (C) 2022 Yifeng Chen et al. This is an open access article distributed under the Creative Commons Attribution License, which permits unrestricted use, distribution, and reproduction in any medium, provided the original work is properly cited.

The current preemption method for traffic signals at intersections located near highway-rail grade crossings (IHRGC) is known as the standard preemption (SP). The SP strategy is designed to give priority to the phases which clear vehicles off the railroad tracks as quickly as possible before a train arrives at HRGCs and provides the drivers and pedestrians with a minimum warning time (MWT). However, the SP considers neither pedestrian safety nor system efficiency at IHRGCs. As a result, this may lead to safety and delay problems at IHRGCs. To solve the problems, a state-of-the-art transition preemption strategy (TPS) algorithm, named TPS_DT, is developed in this paper. The new TPS algorithm is designed for corridors with multiple HGRCs that have dual tracks. An urban highway corridor with multiple HRGCs in Lincoln, NE, was selected as the study corridor. A calibrated VISSIM model of the study corridor was used to test the safety and efficiency of the proposed algorithm. The algorithm was coded in VAP, which is an add-on module of VISSIM. A roadway-railway corridor with multiple IHRGC and dual rail tracks in Lincoln, NE, was used as the testbed. The Measurements of Effectiveness (MOEs) used for evaluation include the rate of pedestrian phase cutoffs, intersection vehicle delay, and corridor vehicle delay. It was found that TPS_DT can significantly improve pedestrian safety and reduce vehicle delay at IHRGCs. Furthermore, the effects of train arrival prediction errors on safety and efficiency of the IHRGCs are also analyzed in the paper.

\section{Introduction}

Highway-rail grade crossings are locations where a highway and railway intersect at the same level $[1,2]$. In the U.S., there were a total of 209,655 highway-rail grade crossings (HRGC) as of 2015 [2]. At HRGCs, rail traffic negatively impacts the efficiency and safety of roadway traffic because trains always have the right-of-way over roadway vehicles. When an intersection is in the proximity of an HRGC, typically defined as being within $200 \mathrm{ft}$, standard practice in the U.S. is to interconnect the railroad signal control equipment and the highway signal control equipment and to use a preemption signal control strategy when a train is approaching the HGRC [3]. There have been a number of studies focusing on preemption operations of traffic signals at intersections near HRGCs (IHRGCs) [2, 4-8]. The traditional standard preemption (SP) strategy, which is the common practice in the U.S., provides vehicles and pedestrians with a minimum warning time $[4,8]$. However, this strategy does not consider the safety and delay at the IHRGC and can lead to the abrupt end of current traffic signal phases including the truncation of pedestrian phases due to variations in train arrival times $[4,8]$. Obviously, truncating pedestrian phases when pedestrians may be in the process of crossing the road is inherently dangerous.

To address this issue at a single IHGRC, the transition preemption strategy (TPS) $[8,9]$ was developed. The TPS uses an additional detector upstream of the SP detector and provides an advance preemption warning time (AWPT). The algorithm greatly reduces the number of pedestrian 
phases that are truncated, but prediction errors in train arrival times can still result in pedestrian phase truncations and/or high vehicle delay. The improved transition preemption strategy (ITPS) $[8,10]$ relies on the additional upstream detector to provide AWPT but incorporated a new train arrival prediction algorithm. This algorithm can increase the accuracy of train arrival prediction by frequently updating the train arrival time and estimating the prediction error bounds. The ITPS assigns higher importance and more green time to the phases that will be blocked during the preemption than those served during the preemption, before the preemption sequence is initiated. Simulation studies [8] have illustrated that ITPS can significantly improve both the safety and efficiency of the intersections near HRGCs. The limitation of the ITPS is that it was tested at a single signalized intersection near a highway-rail grade crossing (IHGRC). It does not consider safety or efficiency at a corridor level or network level. In this paper, a new transition preemption strategy for dual tracks, referred to as the TPS-DT, was developed for railway-roadway corridors with multiple IGHRCs and a dual-track environment with multiple trains passing in both directions.

\section{Background}

2.1. Standard Preemption. The standard preemption (SP) sequence is the current practice for operating railroad crossings and traffic signals near at-grade railroad crossings in the U.S. $[4,8,10]$. Its objective is to clear vehicles that have queued backwards from an IHGRC to a HGRC as quickly as possible $[6,10]$. The detection system used is a first-generation detection system, which includes conventional track circuit systems (e.g., DC circuits and AC-DC circuits), motion sensor systems, constant warning time (CWT) systems, and induction loop systems $[4,8]$. Among these, the DC circuit and the CWT system are considered best practice [11]. The limitation of the SP lies in the fact that it keeps the crossing warning time at a minimum and does not account for uncertainties about the warning time. This may result in insufficient warning time and abrupt truncation of conflicting vehicular or pedestrian phases at IHRGC $[4,10]$.

\subsection{Transition Preemption Strategy. The transition from} normal operation into preemption operation is required when traffic patterns change with the presence of railroad traffic or emergency vehicles. An optimized transition improves the efficiency of signal systems with preemption operation, where the transition between normal signal plan and preemption signal plan occur more frequently and the benefits of improving transition plans are more significant in terms of social cost, such as delays, fuel consumption and air emission [12]. A review of the current transition preemption strategies can be found in $[8,9,13,14]$.

The transition preemption strategy (TPS) for railroad traffic signal preemption is an enhanced preemption strategy developed and field tested at the Texas Transportation Institute in 1999. The objective of TPS is to enhance the safety of pedestrians and drivers by providing an advance preemption warning time to the signal controller before the standard preemption starts [3, 8]. When using TPS, an extra detector is placed further upstream from the SP detector location. The upstream detector is usually a second-generation detection system, such as a sonic detector, Doppler radar detector, or video image detector. The time between the activation time of TPS and the activation time of SP is the advance preemption warning time (AWPT). A study of the TPS strategy by Venglar showed a 39\% reduction in the number of pedestrian clearance times truncated during the preemption sequence [9]. However, the current TPS does not account for the variability of train speeds explicitly, which results in variation of both the advance preemption warning time and standard preemption warning time. Therefore, the truncation of pedestrian clearance phase and vehicular phase were not eliminated in Venglar's study [9]. The variation of preemption warning time may also cause excessive intersection delay [9]. Brennan et al. applied high resolution traffic controller data and a gate-down confirmation circuit at an active HRGC to develop preemption performance measures $[13,15]$.

Furthermore, a preempt trap, which is an unsafe situation when vehicles enter the HRGC after the track clearance phase has ended, may occur if the track clearance phase ends before the gates are completely in the horizontal position [7]. This problem can be addressed by improving the communication between the highway and railway signal control subsystems, e.g., the Advance Preemption with Gates Down Confirmation (APwGDC) design $[11,16]$.

\subsection{Improved Transition Preemption Strategy (ITPS). To} enhance the efficiency and safety of the current TPS strategy, an improved TPS was developed, based on the framework of the current TPS $[8,10]$. The ITPS provides more green time to nondwell signal phases, which are blocked during the preemption sequence, and incorporates a generic train arrival prediction model, such as the multiple regression model or modular artificial neural network (ANN) [8], to estimate the train arrival time as well as its confidence interval. A simulation study shows the improved TPS strategy can eliminate pedestrian phase truncations and significantly decrease delay when the APWT is greater than 80 seconds $[8,10,17]$.

2.4. Other Related Preemption Studies. Kim et al. applied a genetic algorithm-based stochastic optimization approach for a signalized intersection near HRGC with SP operation to minimize highway delays while improving safety [18]. This optimization approach was shown to reduce the delay by a maximum of $17 \%$ compared to optimal timing plans found otherwise.

FDOT conducted a study about the coordinated preemption of traffic signals to enhance HRGC safety in urban areas. This study investigated the potential of advanced features of traffic signal system software platform to improve safety and mobility problems at HRGCs and adjacent arterials [19]. Chen et al. proposed a methodology to detect train arrival by the preemption activations and deactivations 
at the upstream intersections along the train's path and evaluated various preemption strategies through simulation analysis [20].

Existing studies related to the transition preemption strategies at intersections near HRGCs are very limited. Additional study topics in existing literature related to preemption strategies include emergency vehicle preemption and control strategies. A systematic review of route optimization and preemption methods for emergency vehicles can be found in [14]. So et al. studied the preemption strategies for automated emergency vehicles under an automated driving environment [21]. Qin and Khan proposed a real-time control strategy for emergency vehicle preemption [22]. They developed a two-phase algorithm consisting of a relaxation method and a stepwise search strategy to solve the optimal control model. $\mathrm{Mu}$ et al. conducted several studies of emergency vehicle preemption strategies while considering route-based applications, timed colored Petri Nets, and a nondominated sorting genetic algorithm II [23-25].

2.5. Potential Improvements. The logic of the ITPS was designed and tested for single railroad track corridors under the scenario of a single train traversing an individual HRGC. Consequently, it cannot be used in (1) corridors with multiple HRGCs and/or (2) corridors with dual or multiple tracks. Because it is based on a single HRGC, it is not designed to consider corridor-wide safety and efficiency metrics. To address these limitations, a new preemption algorithm, specifically designed for HRGCs with dual or multiple tracks and highway/railway corridors with multiple IHGRCs, is developed in this paper. It should be noted that the new preemption algorithm, similar to TPS and ITPS, is designed to complement and not replace the SP algorithm. In other words, while the new algorithm will be designed to improve safety and efficiency, it will not make the system worse off than what is currently being done in terms of safety or efficiency.

\section{Developing the Advanced Transition Preemption Strategy for Dual Tracks (TPS_DT)}

The proposed transition preemption strategy for dual track, entitled TPS_DT, was developed based on the improved transition preemption strategy (ITPS) developed by Cho [8]. ITPS was designed and tested in the scenario of a single track and a single HRGC and hence was only concerned with a single train in the corridor. The TPS_DT is developed specifically for the dual-track environment where multiple trains may be traveling in the corridor in both directions. In addition, it is designed for a corridor with multiple IHRGCs and associated HGRCs. The TPS_DT has the same basic strategies as ITPS: (1) improving safety by reducing or eliminating the probabilities of pedestrians being stranded on the crosswalks, (2) assigning more phase time to those nondwell phases (i.e., the phases blocked during standard preemption), before the SP is activated, and (3) using a generic train arrival time prediction model that was incorporated in the algorithm. However, because the algorithm is focused on a more complex roadway-railway environment and is concerned with corridor safety and efficiency, it is considerably more sophisticated as outlined below.

3.1. General Design Thoughts and Key Parameters. To maximize the traffic throughput at IHRGC, the TPS_DT algorithm assigns more green time to the nondwell phases, i.e., the phases that are in conflict with the train traffic and prohibited during the preemption, before the standard preemption (SP) procedure starts. To identify the nondwell phases, the algorithm first checks (1) which phase in the cycle is active when the TPS_TD starts, (2) how much time is needed to serve the next two phases in the cycle, and (3) whether there will be any vehicle calls during the current phase or the next two phases.

Considering $n$ phases in the signal timing of a controller, Phase $i, j$, and $k$ are the current phase, the next phase, and the phase after the next phase, respectively. The relationship among these variables is shown in equations (1) and (2):

$$
\begin{aligned}
& j=i+1, \quad \text { if } i<n ; j=1, \text { if } i=n, \\
& k=j+1, \quad \text { if } j<n ; k=1, \text { if } j=n,
\end{aligned}
$$

where $i, j, k \in$ phase $\{1,2,3, \ldots, n\}$.

The minimum time needed to service the next phase and the necessary minimum time to service the next two phases are calculated as follows:

$$
\begin{aligned}
& M_{j}=Y_{i}+R_{i}+G_{j}+Y_{j}+R_{j}, \\
& M_{k}=M_{j}+G_{k}+Y_{k}+R_{k},
\end{aligned}
$$

where $M_{j}$ is the minimum time to service the next phase (phase j) (s), $Y_{i}$ is amber time of the current phase $i(\mathrm{~s}), R_{i}$ is all-red interval of the current phase $i(\mathrm{~s}), G_{j}$ is the minimum green time of the next phase $j(\mathrm{~s}), Y_{j}$ is amber time of the next phase $j(\mathrm{~s}), R_{j}$ is all-red interval of the next phase $j(\mathrm{~s})$, $M_{k}$ is the minimum time to service the phase after the next phase (phase $k$ ) (s), $G_{k}$ is the minimum green time of the phase after the next phase $k(\mathrm{~s}), Y_{k}$ is the amber time of the phase after the next phase $k(\mathrm{~s})$, and $R_{k}$ is the all-red interval of the phase after the next phase $k(\mathrm{~s})$.

The vehicle calls in phases $i, j, k$ are noted as $\mathrm{Call}_{i}, \mathrm{Call}_{j}$, and $\mathrm{Call}_{k}$, respectively. They are binary variables, e.g., Call ${ }_{i}$, equal to 1 which means there is a call for Phase $i$ and Call $i$ equal to 0 which means there is no call for Phase $i$.

The TPS_DT algorithm first identifies the start time of the TPS procedure, and this process is based on two parameters: the time remaining until the start of TPS_DT for EB trains $\left(T_{1 \_\mathrm{EB}}^{l}\right)$ and the time remaining until the start of TPS_DT for WB trains $\left(T_{1_{-} w B}^{l}\right)$. The two parameters are calculated using equations (4) and (5), respectively. The TPS_DT algorithm will start when either $T_{1_{-E B}}^{l}$ or $T_{1_{-} w B}^{l}$ is equal to zero. A value of zero or negative value indicates that the estimated train arrival time is equal to or less than the prespecified advance preemption warning time (APWT). It 
should be noted that the train arrival time $P_{k_{-} \mathrm{EB}}^{l}$ and $P_{k_{-} \mathrm{WB}}^{l}$ in this study is estimated as the quotient of the current distance from the head of the train to the HRGC and the current speed of the train. This is equal to the actual arrival time of a train in the simulation because the speed of a train in the simulation remains constant. However, train speeds are rarely constant in practice. In this field, the arrival time can be estimated by using generic prediction algorithms such as multiple regression models [26], artificial neural network (ANN) models, and random forest (RF) model $[27,28]$. Alternatively, they may be input from a positive train control (PTC) system, which records the train's current position, direction, and speed through its on-board GPS and updates its arrival time estimates continuously [27, 29, 30]:

$$
\begin{aligned}
T_{1 \_\mathrm{EB}}^{l} & =P_{k_{-} \mathrm{EB}}^{l}-\tau_{\mathrm{EB}}^{l} \\
& =A_{k_{\mathrm{EB}}}^{l}-\tau_{\mathrm{EB}}^{l}, \\
T_{1 \_w \mathrm{~B}}^{l} & =P_{k_{-} \mathrm{WB}}^{l}-\tau_{\mathrm{WB}}^{l} \\
& =A_{k_{\mathrm{WB}}}^{l}-\tau_{\mathrm{WB}}^{l},
\end{aligned}
$$

where $T_{1 \_ \text {EB }}^{l}$ is the remaining time to the start of TPS_DT for EB trains at the $l$ th HRGC, $T_{1 \_w B}^{l}$ is the remaining time to the start of TPS_DT for WB trains at the $l$ th HRGC, and $P_{k_{-} \mathrm{EB}}^{l}$ is the estimated EB train arrival time to the $l$ th HRGC at the end of $k$ seconds after the train was detected by the advanced detector. This parameter is updated every $t$ seconds as the train approaches the crossing. $t=1$, in this paper; $P_{k_{-} \mathrm{WB}}^{l}$ is the estimated WB train arrival time to the $l$ th HRGC at the end of $k$ seconds after the train was detected by the advanced detector. This parameter is updated every $t$ seconds as the train approaches the crossing. $t=1$, in this paper; $A_{k_{-} \mathrm{EB}}^{l}$ is the actual EB train arrival time to the $l$ th HRGC at the end of $k$ seconds after the train was detected by the advanced detector; $A_{k_{-} \mathrm{WB}}^{l}$ is the actual WB train arrival time to the $l$ th HRGC at the end of $k$ seconds after the train was detected by the advanced detector; $\tau_{\mathrm{EB}}^{l}$ is the advanced preemption warning time (APWT) specified for EB trains at the lth HRGC, $\tau_{\mathrm{EB}}^{l} \geq 25 \mathrm{~s}$.

$\tau_{\mathrm{WB}}^{l}$ is the advanced preemption warning time (APWT) specified for WB trains at the $l$ th HRGC, $\tau_{\mathrm{WB}}^{l} \geq 25 s$; $l$ HRGC is in the Cornhusker Hwy corridor. $l=1,2,3$, where $1=33^{\text {rd }}$ street HRGC, $2=$ Adams street HRGC, and $3=44^{\text {th }}$ Street HRGC in this paper.

The other two important parameters in the TPS_DT algorithm are the remaining times until the start of standard preemption (SP) for EB and WB trains. These are denoted as $T_{2 \_ \text {EB }}^{l}$ and $T_{2 \_w B}^{l}$ and are calculated using equations (6) and (7), respectively. A zero or negative value of these parameters indicates the predicted train arrival time of EB or WB train is equal to or less than the preset SP warning time (e.g., $25 \mathrm{~s}$, in this paper):

$$
\begin{aligned}
& T_{2_{-} \mathrm{EB}}^{l}=P_{k_{-} \mathrm{EB}}^{l}-c, \\
& T_{2_{-} w \mathrm{~B}}^{l}=P_{k_{-} \mathrm{WB}}^{l}-c,
\end{aligned}
$$

where $T_{2 \_ \text {EB }}^{l}$ is the remaining time to the start of standard preemption (SP) for EB trains at the $l$ th HRGC, $T_{2 \_w B}^{l}$ is the remaining time to the start of standard preemption (SP) for WB trains at the $l$ th HRGC, and $c$ is the time subtracted to ensure $c$ seconds of preemption warning time for the test corridor. In this paper, $c$ is set to 25 seconds.

3.2. Logical Steps of TPS_DT Logic. The logic algorithm of the TPS_DT is presented graphically in the flowcharts shown in Figure 1. The section discusses the individual steps of the TPS_DT logic algorithm in the flowcharts. Note that the logic is iterative in nature and the iteration is updated every $t$ seconds. In this paper, $t$ was set to 1 second.

Step 0-1: the remaining time to the start of TPS_DT $\left(T_{1 \_ \text {EB }}^{l}\right.$ and $\left.T_{1 \_ \text {WB }}^{l}\right)$ is checked. The railroad has dual tracks, so trains may approach from either direction (e.g., eastbound or westbound for the study corridor). If there are two trains approaching from two directions simultaneously, whichever train first fulfills the condition of the remaining time to the start of TPS_DT being equal to or less than zero will start the TPS_DT algorithm. In other words, once either $T_{1 \_ \text {EB }}^{l}$ or $T_{1 \_ \text {WB }}^{l}$ is equal to or less than 0 , the logic proceeds to step $0-2$. Otherwise, if both $T_{1 \_ \text {EB }}^{l}$ and $T_{1_{-} \text {WB }}^{l}$ are greater than zero, the logic skips to steps $0-3$. The logic is expressed in the logic judgement L1.

$$
\text { If } T_{1 \_\mathrm{EB}}^{l} \leq 0 \text { or } T_{1 \_\mathrm{WB}}^{l} \leq 0
$$

then, the logic goes to step 0-2.

otherwise, the logic goes to Step 0-3.

Step 0-2: let the Boolean parameter “TPS” equal 1. Go to Step 0-3 which initiate the main functions of the TPS_DT process.

Step 0-3: update (1) the predicted arrival time $\left(P_{k_{-} \text {EB }}^{l}\right.$ for EB train and $P_{k_{-} \mathrm{WB}}^{l}$ for WB train), (2) the time until the start of TPS_DT ( $T_{1 \_E B}^{l}$ and $\left.T_{1 \_W B}^{l}\right)$, and (3) the time until the start of the standard preemption $\left(T_{2 \_ \text {EB }}^{l}\right.$ and $\left.T_{2 \_ \text {WB }}^{l}\right)$ for EB and WB trains accordingly. As discussed above, $T_{1_{-} \mathrm{EB}}^{l}$ and $T_{1_{-} \mathrm{WB}}^{l}$ are updated every $1 \mathrm{~s}$.

Step 1-0: the main functions of the TPS_DT process is initiated in this step.

Step 1-1: the algorithm checks (1) if the remaining time until the start of the track clearance phase for either the EB train $\left(T_{2_{-} \mathrm{EB}}^{l}\right)$ or WB train $\left(T_{2_{-} \mathrm{WB}}^{l}\right)$ is equal to zero and (2) if the standard preemption has begun (PreemptionActive $=1$ ).

In case a train is arriving later than predicted, condition (1) is satisfied but condition (2) is not. There are two scenarios for this situation: (1) if the current phase is in green, the current phase will remain active until the start of standard preemption; (2) if the current phase is in the change and clearance interval (i.e., amber or all-red clearance), the track clearance phase will start once the change and clearance interval has ended. 

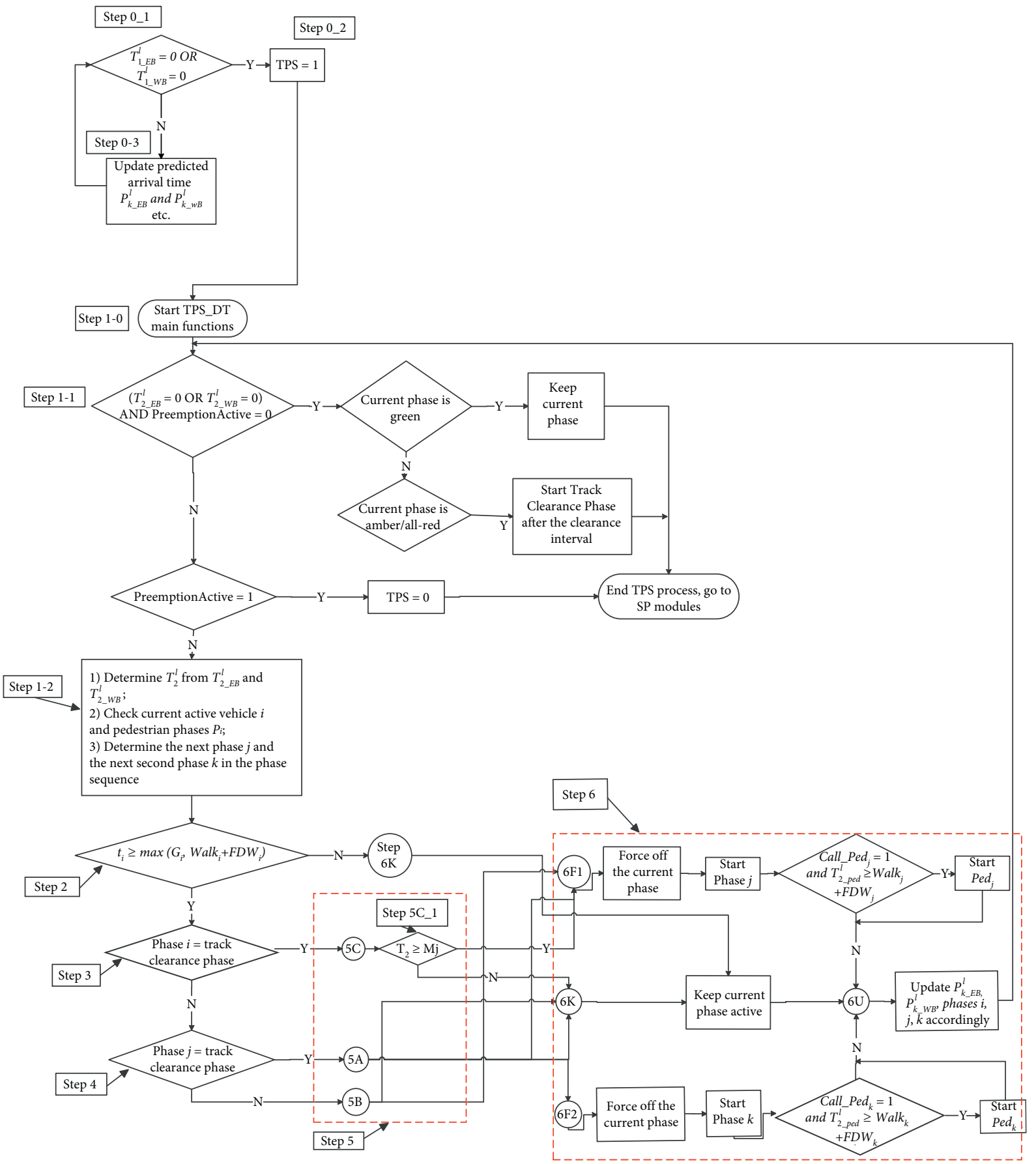

FIGURE 1: Flowchart of the TPS_DT logic algorithm.

In the case of a train arriving earlier than predicted, condition (2) will be satisfied, and the parameter "PreemptionActive" in the SP module is equal to 1. Consequently, the algorithm will exit the TPS_DT module and then go to the standard preemption (SP) module. Otherwise, the TPS_DT module will proceed and the algorithm goes on to Step 1-2. The condition is expressed in the logic judgements L2 and L3.
If $\quad\left(\mathbf{T}_{2 \_ \text {EB }}^{\mathbf{l}}=0\right.$ or $\left.\mathbf{T}_{2 \_ \text {WB }}^{\mathbf{l}}=0\right)$ and (PreemptionActive)

$=0$

then if the current phase is in green, keep the current phase active.

otherwise, if the current phase is in clearance interval (amber or all-red clearance), then start the track clearance phase by the end of the clearance interval.

If PreemptionActive $=1$ 
then TPS $=0$, exit TPS_TD module, go to the SP module; otherwise, the logic proceeds to Step 1-2.

Step 1-2: there are three substeps: (1) determine the critical time remaining to the start of track clearance phase at the $l^{\text {th }}$ HRGC, denoted as $T_{2}^{l}$, which is a function of $T_{2 \_ \text {EB }}^{l}$ and $T_{2-W B}^{l}$; (2) check the current active vehicle $i$ and pedestrian phases $P_{i}$; and (3) determine the next phase $j$ and the next second phase $k$ in the phase sequence. Then, the algorithm proceeds to Step 2.

By definition, $T_{2}^{l}$ is equal to either $T_{2 \_ \text {EB }}^{l}$ or $T_{2_{2} \mathrm{WB}}^{l}$, depending on three possible situations of train arrivals: (1) there is only an EB train, and $T_{2}^{l}$ is equal to $T_{2 \_\mathrm{EB}}^{l}$; (2) there is only an WB train, and $T_{2}^{l}$ is equal to $T_{2}^{l}{ }_{-\mathrm{WB}}$; and (3) there is an $\mathrm{EB}$ and a WB train, and $T_{2}^{l}$. is equal to the lesser of $T_{2 \_\mathrm{EB}}^{l}$ and $T_{2}^{l}{ }_{2 \mathrm{WB}}$. The reason for using the lesser of $T_{2_{-} \mathrm{EB}}^{l_{-}}$and $T_{2_{-} \mathrm{WB}}^{l}$ is that when there is an EB train and WB train, the train with the least remaining time until the start of the track clearance phase will reach the point of terminating the TPS_DT algorithm first. L4 through L6 represents these three scenarios.

If EB trains only, Then,

$$
T_{2_{-} \mathrm{EB}}^{l}=P_{k_{-} \mathrm{EB}}^{l}-c \geq 0, \text { and } T_{2_{-} \mathrm{WB}}^{l}=-c<0
$$
because $P_{k_{-} \mathrm{WB}}^{i}=0$.

(Note: this is true prior to the start of the track clearance phase. After that, $T_{2 \_\mathrm{EB}}^{l}=P_{k_{-} \mathrm{EB}}^{l}-c<0$ and $T_{2-\mathrm{WB}}^{l}<0$. The same holds for L5 and L6).

$$
\text { Thus, } T_{2}^{l}=T_{2 \_ \text {EB }}^{l} \text {. }
$$

If WB train only, then,

$$
\begin{aligned}
& T_{2 \_\mathrm{WB}}^{l}=P_{k_{-} \mathrm{WB}}^{l}-c \geq 0, \text { and } T_{2_{-} \mathrm{EB}}^{l}=-c<0 \\
& \text { because } P_{k_{-} \mathrm{EB}}^{l}=0 . \\
& \text { Thus, } T_{2}^{l}=T_{2 \_\mathrm{WB}}^{l}
\end{aligned}
$$

If trains are from both $\mathrm{EB}$ and $\mathrm{WB}$, then,

$$
\begin{aligned}
& T_{2_{-} \mathrm{EB}}^{l}=P_{k_{-} \mathrm{EB}}^{l}-c \quad \geq \quad 0, \quad \text { and } \\
& T_{2_{-} \mathrm{WB}}^{l}=P_{k_{-} \mathrm{WB}}^{l}-c \geq 0 . \\
& \text { Thus, } T_{2}^{l}=\min \left(T_{2_{\mathrm{EB}}}^{l}, T_{2_{\mathrm{WB}}}^{l}\right)
\end{aligned}
$$

Step 2: check if the current phase has served both the minimum vehicular green time $G_{i}$ and in the case of the pedestrian phase being active the minimum pedestrian phase time (i.e., minimum pedestrian green plus pedestrian clearance time). If the minimum phase time for both vehicles and pedestrians has been served, the logic goes to Step 3. Otherwise, the logic goes to Step $6(\mathrm{k})$, and the current phase remains active. The condition is expressed in L7.

$$
\text { If } \mathbf{t}_{\mathbf{i}} \geq \max \left(\mathrm{G}_{\mathbf{i}}, \mathrm{Walk}_{\mathbf{i}}+\mathrm{FDW}_{\mathbf{i}}\right)
$$

then, the logic goes to Step 3.

otherwise, go to Step 6(k) (i.e. to keep the current phase active).

where $t_{i}=$ elapsed time of the current phase $i$,

$G_{i}=$ minimum green time of phase $i$,

$\mathrm{Walk}_{i}=$ minimum pedestrian green time of the current phase,

$\mathrm{FDW}_{i}=$ pedestrian clearance time of the current phase,

Step 3: the current phase $i$ is checked. If the current phase is the track clearance phase, the logic proceeds to step 5C-1 in Part C. Otherwise, the logic goes to Step 4. The condition is expressed in L8.

If current phase $=$ track clearance phase

then, the logic proceeds to part C, step 5C-1. otherwise, the logic goes to Step 4.

Step 4: the next phase $j$ is checked. From this step, the module is divided into two parts, $5 \mathrm{~A}$ and $5 \mathrm{~B}$, depending on whether the next phase is the track clearance phase. If yes, the logic goes to part 5A. Otherwise, the logic proceeds to part 5B. L9 shows the condition.

If next phase (phase $j)=$ track clearance phase

then the logic proceeds to step $5 \mathrm{~A}-1$ of part $5 \mathrm{~A}$. otherwise, the logic goes to step $5 \mathrm{~B}-1$ of part $5 \mathrm{~B}$.

In the next sections, Step 5 of the algorithm will be discussed in detail, including part $5 \mathrm{~A}$, part $5 \mathrm{~B}$, and part 5C.

Part 5A: for this part, phase $j$ is the track clearance phase. There are three steps, namely, Step 5A_1, Step 5A_2, and Step 5A_3, in part 5A. Figure 2 shows a detailed flowchart of part $5 \mathrm{~A}$.

Step 5A-1: check the vehicle call status for the current phase $i$. If the current phase has a vehicle call $\left(\right.$ call $\left._{i}=1\right)$, the logic goes to step 5A-2. Otherwise, then logic goes to step 5A-3. The condition is shown by L10.

If call $i=1$,

then the logic goes to step 5A-2.

otherwise, the logic goes to step 5A-3.

Step 5A-2: vehicle call for the current phase.

(a) If $T_{2}^{l}>M_{k}$

(1) If there is no call for either of the next two phases $\left(\right.$ call $_{j}=0$ and call $\left._{k}=0\right)$, keep the current phase active. The logic goes to Step $6(\mathrm{~K})$.

(2) If there is a call for either of the next two phases $\left(\right.$ call $_{j}=0$ or call $\left._{k}=0\right)$, the current phase is terminated and the next phase is started. The logic goes to Step 6 (F1).

These conditions are shown by L11.

$$
\begin{aligned}
& \text { If } \mathbf{T}_{2}^{\mathbf{l}}>M_{k} \\
& \text { If call }=0 \text { and } \text { call }_{k}=0,
\end{aligned}
$$

then keep the current phase active and the logic proceeds to Step 6(k). 


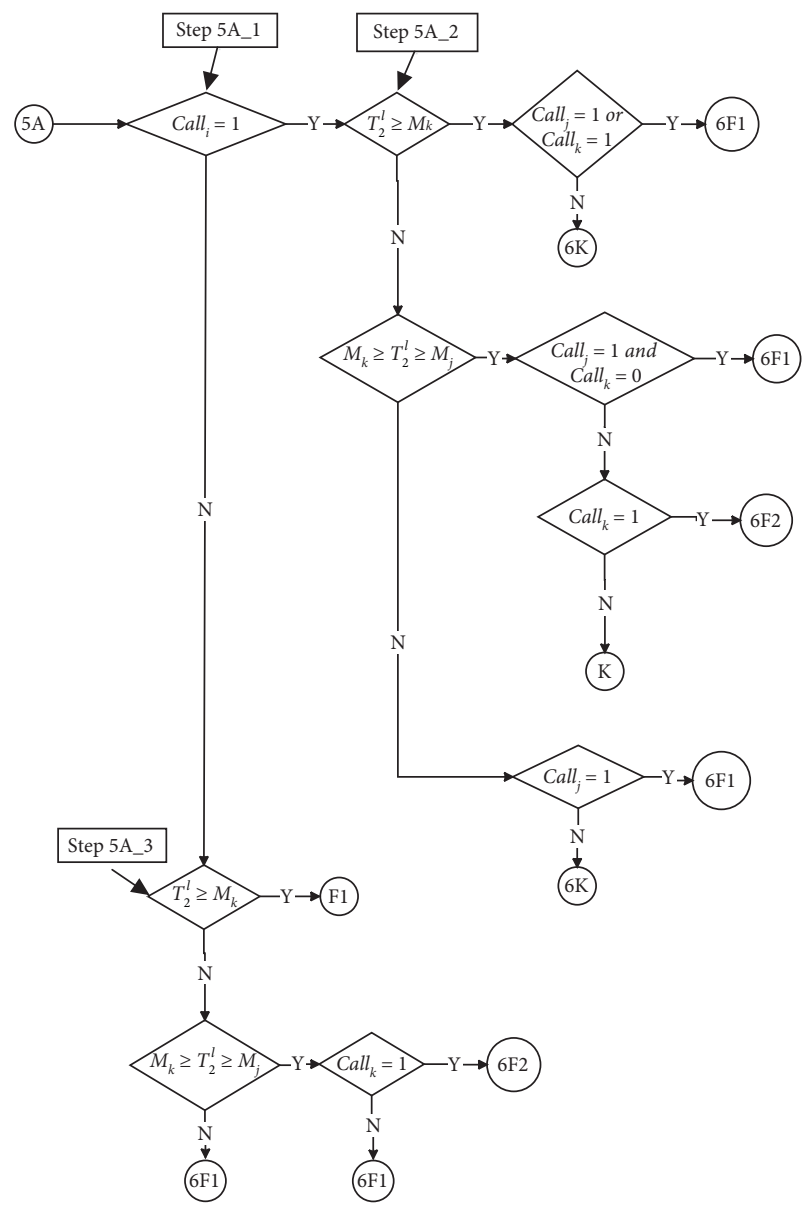

FIgUre 2: Steps of the TPS_DT algorithm Part 5A shown in Figure 1.

else if call $_{j}=1$ or call $_{k}=1$.

then terminate the current phase, start the next phase, and the logic goes to Step $6(\mathrm{~F} 1)$.

(b) If $M_{k} \geq T_{2}^{l} \geq M_{j}$

Depending on a call for the next phase (i.e., the track clearance phase) and the next second phase (i.e., the phase after the track clearance phase), the current phase will be terminated and the logic proceeds to either Step 6 (F1) or Step 6 (F2). The purpose is to give more green time to the next phase and the phase following the next phase, which will be blocked during the standard preemption.

(1) If there is no call for either of the next two phases (i.e., call $_{j}=0$ and call $_{k}=0$ ), the current phase remains active. The logic proceeds to Step $6(\mathrm{~K})$.

(2) If there is a call for the next phase and there is no call for the next second phase (i.e., the phase after the track clearance phase) (i.e., call cand $_{j} 1$ and call $_{k}=0$ ), the current phase is terminated and the next phase (i.e., track clearance phase) will start. The logic goes to Step 6 (F1).

(3) If there is a call for the phase after the track clearance phase (i.e., call $_{k}=1$ ), regardless of a call for the next phase, the current phase is terminated and the phase after track clearance phase is started. The logic proceeds to Step 6 (F2).

These conditions are shown by L12.

If $M_{k} \geq T_{2} \geq M_{j}$,

If call $_{j}=0$ and call $_{k}=0$,

then keep the current phase active and the logic goes to Step $6(k)$

Else if call $_{j}=1$ and call $k=0$,

then terminate the current phase and start the next phase (track clearance phase); the logic goes to Step 6(F1)

Else if call $_{k}=1$,

then terminate the current phase and start the next phase following the track clearance phase (phase $k$ ); the logic goes to Step 6 (F2)

(c) If $T_{2}^{l}<M_{j}$

(1) If there is no call for the next phase $\left(\right.$ call $\left._{j}=0\right)$, the current phase remains active. The logic goes to Step $6(\mathrm{~K})$.

(2) If there is a call for the next phase $\left(\mathrm{call}_{j}=1\right)$, the current phase is terminated and the next phase starts. Note that since the track clearance phase will continue after TPS ends, there is no need to guarantee the minimum green time. The logic proceeds to Step $6(\mathrm{~F} 1)$.

These conditions are shown by L13.

$$
\begin{aligned}
& \text { If } \mathbf{T}_{2}^{\mathbf{l}}<M j \\
& \text { If } \text { call }_{j}=0,
\end{aligned}
$$

then keep the current phase active and the logic goes to Step $6(\mathrm{~K})$

Else if call $_{j}=1$,

then terminate the current phase and start the next phase, and the logic goes to Step 6 (F1)

Step 5A-3: no vehicle call for the current phase.

(a) If $T_{2}^{l}>M_{k}$

The current phase is terminated, and the next phase will start regardless of a call for the next phase. The logic proceeds to Step 6 (F1). The condition is shown in L14.

$$
\text { If } \mathbf{T}_{2}^{\mathrm{l}}<M_{k}
$$

then terminate the current phase and start the next phase, and the logic goes to Step 6 (F1).

(b) If $M_{k} \geq T_{2}^{l} \geq M_{j}$

Depending on a call for the next second phase, the current phase will be terminated and the logic proceeds to either Step 6 (F1) or Step 6 (F2). The purpose of this is to give more green time to the phase that follows the track clearance phase because this phase will be blocked during the preemption. 
(1) If there is no call for the next second phase $\left(\right.$ call $\left._{k}=0\right)$, the current phase is terminated and the next phase will start, regardless of a call for the next phase. The logic proceeds to Step 6 (F1).

(2) If there is a call for the next second phase $\left(\right.$ call $\left._{k}=1\right)$, the current phase is terminated and the next second phase will start, regardless of a call for the next phase. The logic proceeds to Step 6 (F2).

The conditions are shown in L15.

$$
\begin{aligned}
& \text { If } M_{k} \geq \mathbf{T}_{2}^{1} \geq M_{j}, \\
& \text { If } \text { call }_{k}=0,
\end{aligned}
$$

then terminate the current phase and start the next phase, and the logic goes to Step 6 (F1)

Else if call $k_{k}=1$,

then terminate the current phase and start the next phase of the track clearance phase (phase $k$ ), and the logic goes to Step 6 (F2)

(c) $T_{2}^{l} \leq M_{j}$

The current phase is terminated and the next phase is started regardless of a call for the next phase. The logic proceeds to Step 6 (F1). In this case, the track clearance phase is guaranteed to be operating when the standard preemption is initiated. This ensures that a pedestrian phase cutoff will not occur. The condition is shown in L16.

$$
\text { If } \mathbf{T}_{2}^{\mathbf{l}}>M_{j}
$$

then terminate the current phase and start the next phase, and the logic goes to Step 6 (F1).

Part 5B: the phase following the next phase (i.e., phase $k$ ) is the track clearance phase. There are three steps in part 5B. Figure 3 shows a detailed flowchart of part 5B.

Step 5B-1: check the vehicle call status for the current phase $i$. If the current phase has a vehicle call $\left(\right.$ call $\left._{i}=1\right)$, the logic goes to step 5B-2. Otherwise, the logic goes to $5 \mathrm{~B}-3$. The condition is shown by L17.

$$
\text { If } \text { call }_{i}=1 \text {, }
$$

then the logic proceeds to step 5B-2.

otherwise, the logic goes to step 5B-3.

Step 5B-2: vehicle call for the current phase.

(a) If $T_{2}^{l}>M_{j}+B_{i}$ or $T_{2}^{l} \leq M_{\mathrm{j}}$, the current phase remains active. The logic proceeds to Step $6(\mathrm{~K})$. Here, $B_{i}$ is the buffer time needed to clear extra demand in phase $i$. The conditions in this case indicate there is either abundant time left to clear the next phase $\left(T_{2}^{l}>M_{j}+B_{i}\right)$ or not enough time to clear the next phase $\left(T_{2}^{l} \leq M_{j}\right)$. If $T_{2}^{l}>M_{j}+B_{i}$, the current phase will remain active until $T_{2}^{l} \leq M_{j}+B_{i}$. Once these criteria are met, the algorithm proceeds to Step 6 (F1).

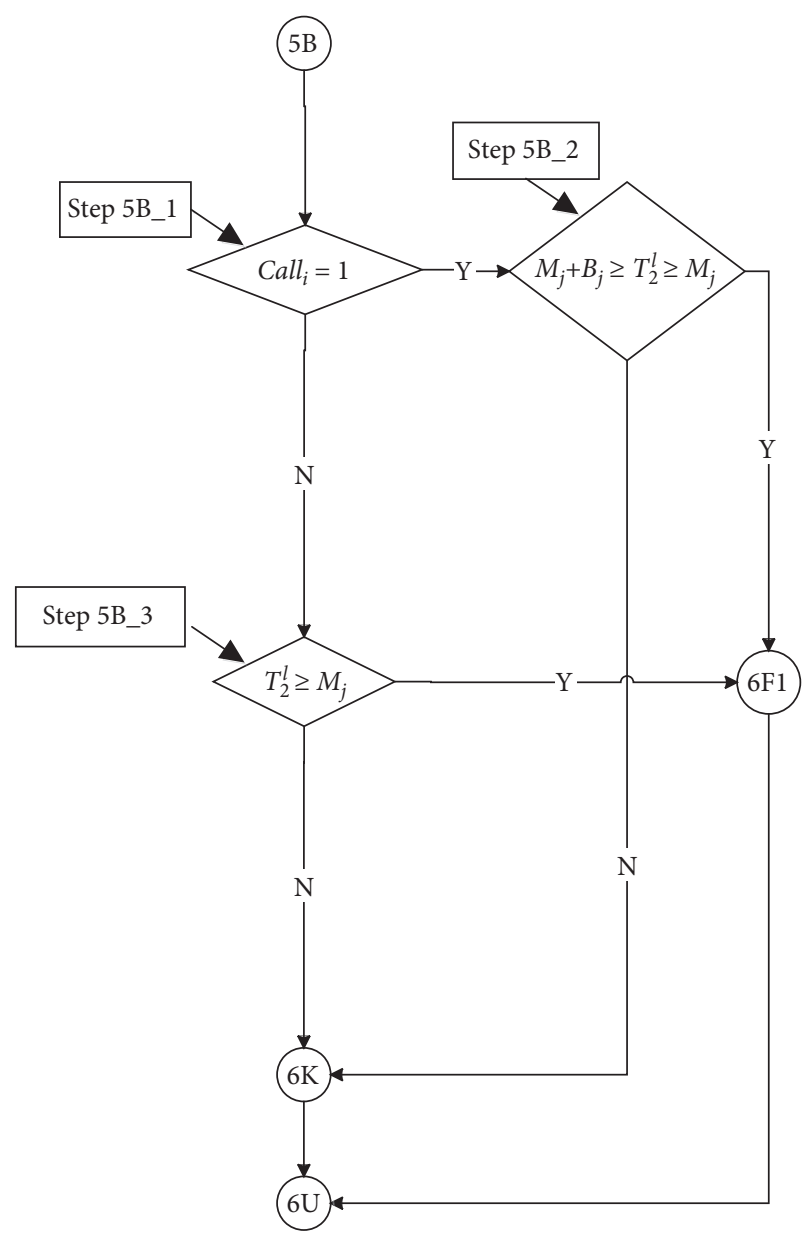

Figure 3: Steps of the TPS_DT algorithm Part 5B shown in Figure 1.

(b) If $M_{j}+B_{i} \geq T_{2}^{l} \geq M_{j}$, the current phase will be terminated and the next phase will start timing. The logic proceeds to Step 6 (F1).

These conditions are shown in L18.

$$
\text { If } \mathbf{T}_{2}^{\mathbf{l}}>M_{j}+B_{i} \text { or } \mathbf{T}_{2}^{\mathrm{l}} \leq M_{j}
$$

then keep the current phase active and the logic goes to Step $6(\mathrm{~K})$. otherwise, if $M_{j}+B_{i} \geq T_{2} \geq M_{j}$,

then terminate the current phase and start the next phase, and the logic goes to Step 6 (F1).

Step 5B-3: no vehicle call for the current phase.

(a) If $T_{2}^{l} \geq M_{j}$, the current phase will be terminated, and the next phase will start. The logic goes to Step 6 (F1).

(b) If $T_{2}^{l}<M_{j}$, the current phase will remain active, and the logic proceeds to Step $6(\mathrm{~K})$.

The conditions are shown by L19.

$$
\text { If } \mathbf{T}_{2}^{\mathbf{l}}<M_{j} \text {, }
$$

Then, terminate the current phase and start the next phase, and the logic goes to Step 6 (F1). 
Else if $T_{2}^{l}<M_{j}$,

Then, keep the current phase active, and the logic goes to Step $6(\mathrm{~K})$.

Part 5C: in this part, the current phase (phase $i$ ) is the track clearance phase.

(a) If $T_{2}^{l} \geq M_{j}$, the current phase will be terminated and the next phase will start. The logic goes to Step 6 (F1).

(b) If $T_{2}^{l}<M_{j}$, the current phase will remain active and the logic proceeds to Step $6(\mathrm{~K})$.

The conditions are shown in L20.

$$
\text { If } \mathbf{T}_{2}^{\mathbf{l}}<M_{j} \text {, }
$$

then terminate the current phase, start the next phase, and proceed to Step 6 (F1).

otherwise, if $T_{2}^{l}<M_{j}$,

then keep the current phase active, and the logic proceeds to Step $6(\mathrm{~K})$.

Step 6 (F1): in this substep, the current phase is "forced off" or ended, and phase $j$ is initiated. If there is a pedestrian call Call_Ped $\left(\right.$ Call_Ped $\left._{j}=1\right)$, check the remaining time for the pedestrian phase $T_{2-\text { ped }}^{l}$. If $T_{2}^{l}$ _ped is equal to or greater than the sum of the pedestrian green and clearance phase $\left(\mathrm{Walk}_{j}+\mathrm{FDW}_{j}\right.$ ), start the pedestrian phase $P_{j}$. Otherwise, omit the pedestrian phase Ped $_{j}$. After this step, the logic transitions to Step 6 (U).

The condition discussed above is shown by L21.

Force off thecurrent phase, and start phase $j$ (L21)

$$
\text { If Call_Ped }{ }_{j}=1 \text { and } \geq \mathrm{Walk}_{j}+\mathrm{FDW}_{j} \text {, }
$$

Then, start the pedestrian phase $\operatorname{Ped}_{j}$. otherwise, omit the pedestrian phase $\mathrm{Ped}_{j}$.

Go to Step $6(\mathrm{U})$.

It should be noted that $T_{2 \text { _ped }}^{l}$ is set such that it cannot be greater than $T_{2}^{l}$. This is done to make sure that there will be no pedestrian phase cutoff. L22 shows the calculation of $T_{2 \text { _ped }}^{l}$. The safety factor $\tau$ makes sure that the pedestrian phases would be terminated $\tau$ seconds earlier than the start of the SP. Consequently, the pedestrian phase will not be cut off abruptly even if a train arrives $\tau$ seconds earlier than predicted. Intuitively, the higher the value of $\tau$, the lower the probability of a pedestrian cutoff and the higher the pedestrian delay. In this paper, $\tau$ is set to 10 seconds to trade off the pedestrian delay for pedestrian cutoff.

$$
T_{2 \text {-ped }}^{l}=T_{2}^{l}-\tau
$$

where

$$
\tau \text { : safety factor }(s), \tau \geq 0 .
$$

The other option is to set $T_{2}^{l}$ ped as the remaining time upon detection of the train by the CWT railroad detector, depending on the distance of the detector to the crossing and the current train speed. The calculation of $T_{2}^{l}{ }_{2}$ ped in this option is shown in L23. In this way, the pedestrian phases will be terminated earlier than the start of the track clearance phase.

$$
\mathrm{T}_{2 \_ \text {ped }}^{1}=\mathrm{T}_{2}^{\mathrm{l}}-\mathrm{D} / \mathbf{v}_{0}
$$

where

$$
D=\text { distance from the train detector to }
$$
the crossing $(\mathrm{m})$

$$
v_{0}=\text { velocity of the train upon detection }
$$

$(\mathrm{m} / \mathrm{s})$

Note that an even more conservative option would be to omit all pedestrian phases once the TPS algorithm starts. This would eliminate the possibility of a pedestrian phase cutoff completely. As shown in $\mathrm{L} 24, T_{2 \_ \text {ped }}^{l}$ is set equal to the maximum of $T_{1_{\text {_EB }}}^{l}$ and $T_{1 \_ \text {WB }}^{l}$. This option was also suggested in the work by Cho (8).

$$
\mathrm{T}_{2 \_ \text {ped }}^{\mathrm{l}}=\max \left(\mathrm{T}_{1 \_\mathrm{EB}}^{\mathrm{l}}, \mathrm{T}_{1 \_\mathrm{WB}}^{\mathrm{l}}\right)
$$

However, omitting the pedestrian phases too early may result in the pedestrians waiting at an intersection for a long time, without seeing the train. The pedestrians may assume the pedestriancrossing signal has malfunctioned and eventually violate the signal. On the contrary, allowing pedestrian phases until the start of standard preemption may lead to pedestrian cutoff if a train arrives earlier than predicted. Deciding whether to omit the pedestrian phase is a tradeoff between safety and efficiency.

Step $6(\mathrm{~K})$ :keep the current phase $i$ active, and the logic goes to Step $6(\mathrm{U})$.

Step 6 (F2): in this step, the current phase is "forced off" and phase $k$ is initiated. If there is a pedestrian call (Call_Ped $k=1)$, the remaining time for the pedestrian phase $T_{2 \text { _ped }}^{l}$ is checked. If $T_{2 \text { _ped }}^{l}$ is equal to or greater than the sum of the pedestrian green and clearance phase $\left(\mathrm{Walk}_{k}+\mathrm{FDW}_{k}\right)$, the pedestrian phase $P e d_{k}$ is started. Otherwise, the pedestrian phase $\mathrm{Ped}_{k}$ is omitted. After this step, the logic proceeds to Step 6 (U). L25 shows the condition.

Force off the current phase; and start phase $j$ (L25)

$$
\begin{aligned}
& \text { If Call } \operatorname{Ped}_{k}=1 \text { and } T_{2-\text { ped }}^{l} \geq \mathrm{Walk}_{k}+\mathrm{FDW}_{k} \\
& \text { then start the pedestrian phase } \mathrm{Ped}_{k} \text {. } \\
& \text { otherwise, omit the pedestrian phase } \mathrm{Ped}_{k}
\end{aligned}
$$

Step $6(\mathrm{U})$ : this is the last step in the loop logic. In this step, the algorithm checks if the current phase should be terminated during this iteration of the algorithm. If the answer is yes, the current phase is ended, and the amber and all-red phases are initiated in sequence. Then, the phase counters $i, j$, and $k$ are updated accordingly. Lastly, $P_{k_{-} \mathrm{EB}}^{l}, P_{k_{\mathrm{WB}}}^{l}$, and $T_{2}^{l}$ are updated. 
3.3. Integration of the TPS_DT Logic in Signal Controller Modules. Figure 4(a) show a schematic of how the proposed TPS_DT algorithm works along with the other modules of the signal controller for the situations of one or more trains passing through the HRGC. When no train is present, the normal operation module is run. When one train is present, the normal operation module will be active until the TPS_DT module is initiated. Three conditions, denoted as C1, C2, and C3, need to be fulfilled to start the TPS_DT. These conditions are

C1: at least one train has been detected at one of the two upstream detector locations (e.g., location A and location B)

C2: the estimated train arrival time for any train in the corridor is equal to or less than the advance preemption warning time (APWT)

C3: the detection zone is free of any trains (e.g., there is no SP in progress)

Figure 4(b) illustrates the detector layout for the proposed TPS_DT logic algorithm. An upstream detector, such as the Doppler radar detector, is placed at the upstream locations from eastbound (EB) and westbound (WB) for TPS operation. Meanwhile, the railroad detector at the HRGC in Figure 4(a) is set up for SP operation. Once the train is detected by the upstream detector, and the estimated train arrival time for any train in the corridor is equal to or less than the constant warning time (CWT); the signal controller will exit the TPS_DT module and initiate the standard preemption (SP) part 1 module. This module starts the track clearance phase and subsequently the dwell phases. The SP part 1 module operates until the train clears the railroad preemption detection zone. Once this is complete, the signal controller moves forward to the SP part 2 module, which starts the exit phases and releases the SP. Once the SP procedure is finished, the signal controller transitions back to the normal operation module.

\section{Simulation Analysis of the TPS_DT Logic}

4.1. Study Corridor and Simulation Network. A $2.4 \mathrm{~km}$ by $3.2 \mathrm{~km}$ urban railway-road network in Lincoln, Nebraska, was chosen as the simulation network. Figure 5 illustrates a map of the simulation network and the study corridor. The network is bounded on the west by North 27th Street, on the east by North 48th Street, on the north by Superior Street, and on the south by Holdrege Street. A $3.2 \mathrm{~km}$ long section of the Burlington Northern Santa Fe (BNSF) railroad, which is a dual-track mainline railroad, goes through the northeast and southwest corners of the network. The railroad crosses North 27th Street with an overpass and North 48th Street with an underpass. The overpass and the underpass together form the geographic boundaries of the simulation network.

In Figure 5, the study corridor, highlighted by the red arrow lines, is Cornhusker Highway (i.e., Nebraska State Highway 6), which runs parallel to the BNSF railroad immediately east of the Adams Street HRGC ('H2' in Figure 5).
Along the study corridor, there are three HRGCs, intersecting North 33rd Street, Adams Street, and North 44 Street, respectively. They are marked as "H1," "H2," and "H3" in Figure 5. Meanwhile, there are three intersections near the three HRGCs: 33rd Street and Cornhusker Highway, 35th Street and Cornhusker Highway, and 44th Street and Cornhusker Highway. They are marked as intersections 3,4 , and 5 and referred to as the target intersections in Figure 5. Besides the three target IHGRCs, there are another three signalized intersections involved in the study corridor and located at the intersection of 27th St and Cornhusker Hwy, 29th St and Cornhusker Hwy, and 48th St and Cornhusker Hwy, respectively.

There were four reasons for choosing the roadwayrailway corridor in Figure 5 for the analysis in this paper:

(1) Cornhusker Hwy is a four-lane major arterial in Lincoln and an alternative route to I- 80 between Lincoln and Omaha, Nebraska, with a relatively high annual average daily traffic (AADT) volume of 20,000 to 35,000 vehicles [31].

(2) There are approximately 50 to 70 trains traveling daily on the BNSF railroad mainline, and this volume is increasing [32]. This indicates that hourly an average of 2-3 trains may go through the HRGCs along the study corridor.

(3) The Adams Street HRGC has been rated as one of the most hazardous HRGCs in Lincoln by the FRA's Web-Based Accident Prediction System (WBAPS) [33].

(4) This corridor has served as the UNL Nebraska Transportation Center HRGC test bed system and is heavily instrumented with train and roadway detection sensors [32].

In summary, safety and delay are two critical problems for the study corridor, due to high roadway and railway traffic volumes.

4.2. Simulation Model. The microsimulation software VISSIM from PTV was used as the simulation tool for this paper because of its ability to emulate multiple traffic modes including passenger car, truck, train, and pedestrian [34]. To create the network in VISSIM, photographs of the corridor, obtained from Google maps, were imported into the program. The highway lanes and railroad tracks were coded based on the mapped images. The characteristics of the network, including traffic volumes, speed limits, detector lengths and locations, lane width, and track width, were either obtained from Google maps or provided by the Public Works Department of the city of Lincoln. It should be noted that the network also includes pedestrian crossings and pedestrian signals at the three target intersections near the HRGCs. The current signal timing settings were also obtained from the Public Works Department of Lincoln and then coded in VISSIM's vehicle actuated programming (VAP) module, which is an add-on module of VISSIM for signal control [34]. Both the current and proposed 


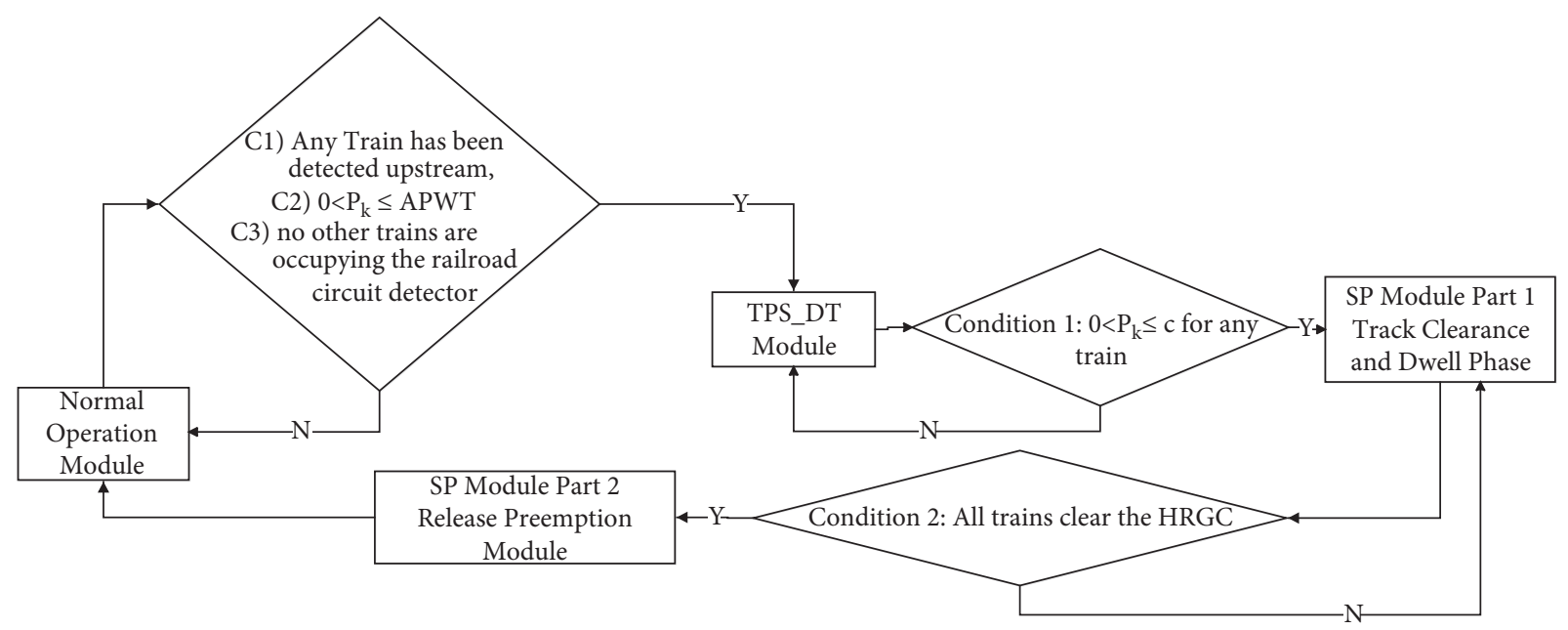

(a)

Condition $\mathrm{C} 1, \mathrm{C} 2$ \& $\mathrm{C} 3$

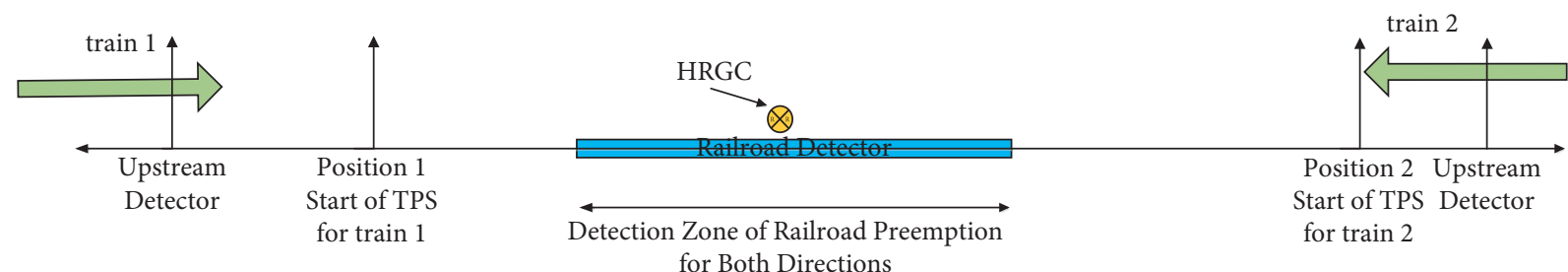

(b)

FIGURE 4: Workflow of the signal controller modules with the integrated TPS_DT algorithm. (a) Flowchart of the signal controller modules; (b) detector layout for TPS and SP.

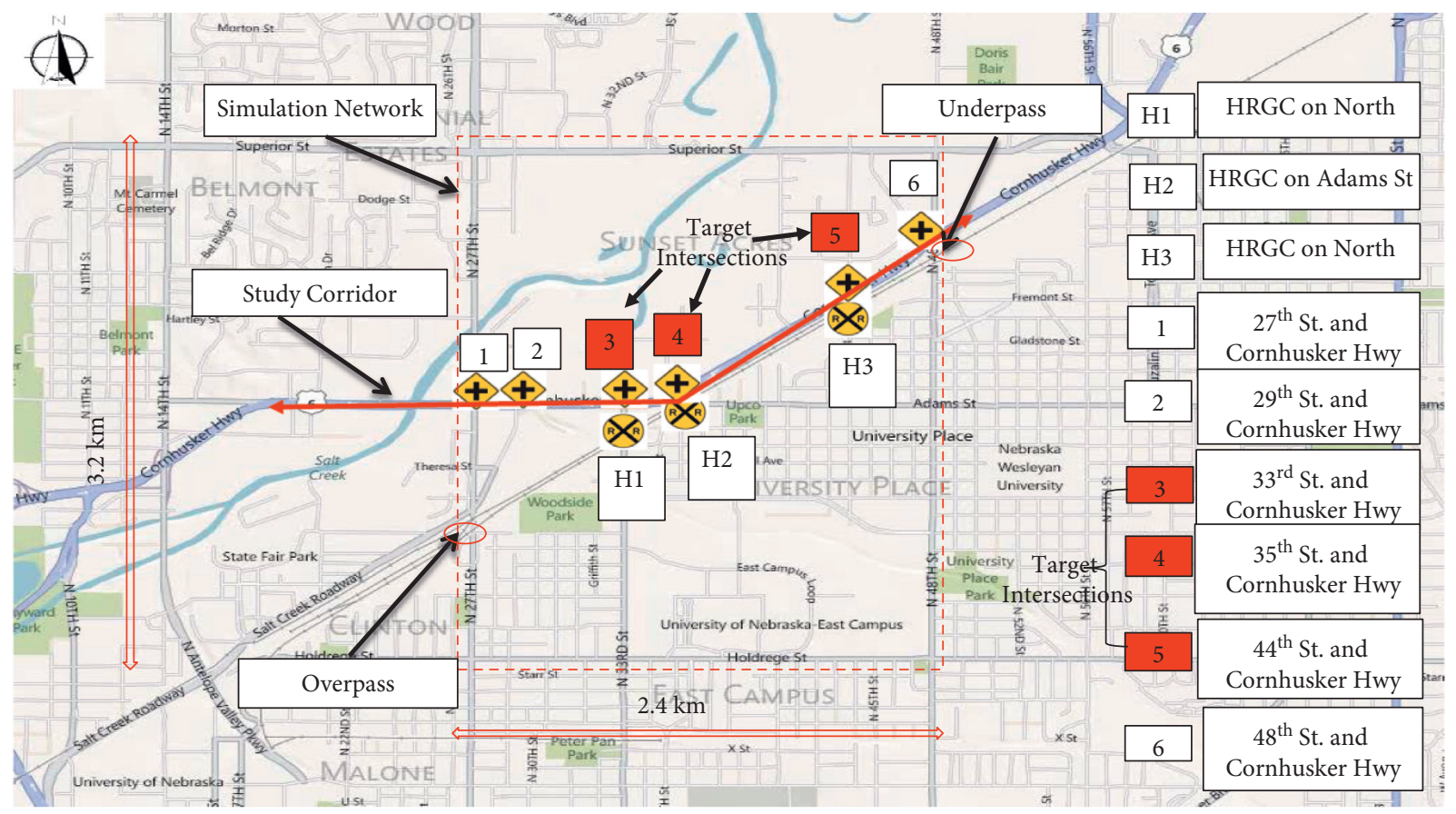

Figure 5: Map of the simulation network and study corridor. 
TABLE 1: Train volume distributions.

\begin{tabular}{|c|c|c|c|c|c|c|c|c|}
\hline & & \multicolumn{6}{|c|}{$\begin{array}{l}\text { WB train volume } \\
(\text { train/h) }(\%)\end{array}$} & \multirow[t]{2}{*}{ Sum (EB train volume distribution) (\%) } \\
\hline & & 0 & 1 & 2 & 3 & 4 & 5 & \\
\hline \multirow{7}{*}{ EB train volume (train/h) } & 0 & 4 & 12 & 7 & 7 & 1 & 0 & 31 \\
\hline & 1 & 8 & 16 & 16 & 9 & 1 & 0 & 50 \\
\hline & 2 & 4 & 3 & 7 & 2 & 0 & 0 & 16 \\
\hline & 3 & 1 & 0 & 1 & 0 & 0 & 0 & 3 \\
\hline & 4 & 0 & 0 & 1 & 0 & 0 & 0 & 1 \\
\hline & 5 & 0 & 0 & 0 & 0 & 0 & 0 & 0 \\
\hline & Sum (WB train volume distribution) & 17 & 30 & 32 & 18 & 2 & 0 & 100 \\
\hline
\end{tabular}

preemption strategies were emulated in the simulation model and coded as a module of the VAP logic.

Empirical train speed, train length, and morning peak hour traffic volumes from the 2009 traffic count data were used in the calibration process. The VISSIM driver behavior parameters, including minimum headway and maximum deceleration rate, were also used as the parameters in the calibration process. A genetic algorithm (GA) method [35] was applied to adjust the VISSIM parameters such that the simulated traffic movement volume data at major intersections are close to the empirical volume data [36-39]. More details on the model calibration and validation can be found elsewhere $[36,37,40]$.

4.3. Simulation Scenarios and Design. In the simulation study, two categories of simulation scenarios were set up: baseline scenarios and optimization scenarios. The SP and the current signal timing plan were implemented as the benchmark in the baseline scenarios, while TPS_DT was implemented in the optimization scenarios for comparison purposes. Moreover, the signal timing parameters, including preemption-related parameters, were optimized in the optimization scenarios, using a GA method. Details regarding the GA-based optimization algorithm can be found elsewhere $[18,35,36,40]$.

A preliminary study of train volumes was conducted in October 2013. A total of 140 trains were observed. Table 1 is a two-way relative frequency table showing the joint and marginal probability distributions of train volumes collected from the preliminary study. Because the test corridor is dual track, trains can approach the HRGCs from the eastbound (EB) direction, the westbound (WB) direction, or simultaneously from both directions. It may be seen in Table 1 that the combinations of one EB train plus one WB train and one EB train plus two WB trains have the highest joint probabilities of 16 percent. It can also be observed that the train volumes of 3 train/h or higher from both directions rarely occurs on the study corridor.

Based on the empirical train volume distribution in Table 1 , three train volumes, i.e., $1 \mathrm{train} / \mathrm{h}, 3 \mathrm{train} / \mathrm{h}$, and 5 train/h, were used and these represent low, medium, and high train volumes, respectively [36]. With different combinations of train volumes and train directions, a total of 9 simulation scenarios were set up for the baseline and optimization scenarios. Table 2(a) lists the 9 baseline scenarios
TABLE 2: Simulation scenarios.

\begin{tabular}{ccccc}
\hline & \multicolumn{5}{c}{ Train volume (train/h/direction) } \\
& \multicolumn{5}{c}{1} & 3 & 5 \\
\hline \multirow{4}{*}{ Train direction } & (a) Baseline scenarios with SP \\
& EB & S-E-1 & S-E-3 & S-E-5 \\
& WB & S-W-1 & S-W-3 & S-W-5 \\
& Both & S-B-1 & S-B-3 & S-B-5 \\
Train direction & Optimization & scenarios with & TPS_DT. & \\
& EB & T-E-1 & T-E-3 & T-E-5 \\
& WB & T-W-1 & T-W-3 & T-W-5 \\
& Both & T-B-1 & T-B-3 & T-B-5 \\
\hline
\end{tabular}

based on the SP algorithm, while Table 2(b) lists the other 9 scenarios utilizing the proposed TPS_DT algorithm. Each scenario is labeled in the form of " $x-y-z$," where " $x$ " represents the preemption strategy used (e.g., "T" represents TPS_DT and "S" represents SP), " $y$ " represents the train direction (e.g., "E" represents EB train, "W" represents WB train, and "B" represents trains from both directions), and " $z$ " represents the number of the trains in each direction (e.g., 1, 3, or 5 train/h). In the evaluation process, each optimization scenario is compared to the baseline scenario with the same combination of train volume and train direction (e.g., T-E-1 vs. S-E-1). For each simulation scenario, a total of 50 simulations with random seeds were run and the average values of the evaluation metrics were calculated out of the 50 simulations as the evaluation outputs for each scenario.

4.4. Simulation Duration. The simulation time for the simulation scenarios was set to 3600 seconds, representing the AM peak hour. In a preliminary simulation study, the network was found to reach a steady state condition approximately $600 \mathrm{~s}$ after the simulation started [36]. The recovery period after a train left the HRGC was approximately $300 \mathrm{~s}$ [36]. Therefore, the analysis period of the simulation starts at $600 \mathrm{~s}$, and ends at $3300 \mathrm{~s}$, with a total analysis length of $2700 \mathrm{~s}$. Figure 6 shows the relationship between analysis period and simulation period. In each of the scenarios discussed in this paper the train departure time is fixed as shown in Table 3. This allowed for a direct comparison between baseline and optimization scenario results under the same traffic conditions. For the scenarios with $1 \mathrm{train} / \mathrm{h}$, the train departs at $1800 \mathrm{~s}$, which is in the middle of the simulation period. For the scenarios with 3 


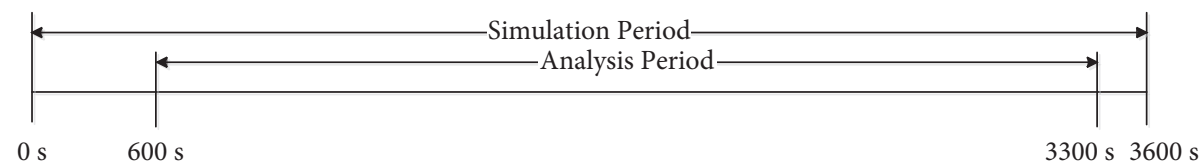

FIgURE 6: Time frame for analysis period during one-hour simulation.

Table 3: Train departure time for different train volumes.

\begin{tabular}{ccccc}
\hline & & \multicolumn{4}{c}{ Train volume (train/h) } \\
& & 1 & 3 & 5 \\
\hline & 600 & 0 train & 1 train & 1 train \\
Train departure time $(\mathrm{s})$ & 1200 & 0 train & 0 train & 1 train \\
& 1800 & 1 train & 1 train & 1 train \\
& 2400 & 0 train & 0 train & 1 train \\
& 3000 & 0 train & 1 train & 1 train \\
\hline
\end{tabular}

trains/h and 5 trains/h, the first train departs at $600 \mathrm{~s}$ and the last train departs at $3000 \mathrm{~s}$. The trains in between depart every $1200 \mathrm{~s}$ for the 3 trains/h scenario and $600 \mathrm{~s}$ for the 5 trains/h scenario.

\subsection{Evaluation Metrics of Simulation}

4.5.1. Safety Metrics. The primary objective of the proposed preemption strategy is to improve pedestrian safety at HRGCs. In this paper, the number and percentage of pedestrian phase truncations $[8,10,16,17]$, which indicate potential risk of pedestrian-vehicle crash, were selected as the safety metrics of TPS_DT. Note that a pedestrian phase truncation is a very dangerous situation. This is because the phase is truncated immediately even if pedestrians are traversing the crosswalk. There is no advance warning provided to the pedestrians, and they are on their own to find the best way to safely finish crossing the street. It is hypothesized that the original designers of the SP algorithm decided that it was better to reduce the probability of a trainroadway vehicle crash at the expense of increasing the probability of a pedestrian-roadway vehicle crash. Regardless, a pedestrian phase truncation is an extremely unsafe situation for both pedestrians and roadway vehicles, and therefore, reducing or eliminating them was the primary safety focus of the algorithm described in this paper.

Equation (8) is used to calculate the probability that a pedestrian enters the intersection and activates the pedestrian signal phase during a given cycle. In the simulation, the pedestrian volumes for all pedestrian phases were set to 400 $\mathrm{ped} / \mathrm{h}$ in the simulation model to ensure that a pedestrian phase is active upon preemption. With $\lambda=400 \mathrm{ped} / \mathrm{h}$ and $t=115 \mathrm{~s}$, the probability of at least one pedestrian arriving and activating the pedestrian phase $P_{\text {ped }}(n \geq 1)$ is approximately $100 \%$, as calculated using equation (8). Consequently, the probability of a pedestrian phase being truncated upon start of the track clearance phase could be as high as $100 \%$ for the HRGCs with the SP system. It is hypothesized that TPS_DT will significantly decrease or eliminate the pedestrian phase truncations at the IHRGCs during preemption:

$$
P_{\text {ped }}(n \geq 1)=1-P_{r}(n=0)=1-e^{(-\lambda \times t)},
$$

where $n$ is the number of pedestrians arriving during the affecting time period of every cycle, $P_{\text {ped }}(n \geq 1)$ is the probability of one or more pedestrians arriving during the affecting time of every cycle, $\lambda$ is the pedestrian arrival rate (ped/h), $T$ is the length of time period that a pedestrian can affect the next pedestrian phase $(=115 \mathrm{~s})$, and $e$ is the natural base of logarithms $(=2.71828 \ldots)$.

4.5.2. Performance Metric. The secondary objective of the TPS_DT algorithm is to improve efficiency of the study corridor. In this paper, vehicular delay (veh/s) is chosen as the performance metric for evaluating the efficiency of TPS_DT. Equation (9) is used to calculate the average delay at an intersection where the delay value is weighted by the traffic movement volumes. Moreover, the average corridor delay is calculated in (10) using the average intersection delay calculated in (9). Similar to equation (9), this metric is weighted by the traffic volumes at the respective intersections:

$$
\begin{aligned}
& d_{j}=\frac{\sum_{i=1}^{n} V_{i j} d_{i j}}{\sum_{i=1}^{n} V_{i j}}, \\
& D=\frac{\sum_{j=1}^{m}\left(\sum_{i=1}^{n} V_{i j}\right) * d_{j}}{\sum_{j=1}^{m} \sum_{i=1}^{n} V_{i j}},
\end{aligned}
$$

where $i$ is the movement of the NEMA signal phases [41], $i=1,2, \ldots, N, j$ is the intersection, $j=1,2, \ldots, M, d_{j}$ is the average delay at intersection $j$ (s/veh), $V_{\mathrm{ij}}$ is the volume of movement $i$ at intersection $j(\mathrm{veh} / \mathrm{h}) d_{\mathrm{ij}}$ is the average delay for movement $i$ at intersection $j$ (s/veh), $D$ is the average delay of the evaluation intersections in the corridor (s/veh), $n$ is the number of the signal phases at an intersection ( $N \leq 8$ in this paper), and $m$ is the number of the evaluation intersections in the corridor.

\subsection{Simulation Results}

4.6.1. Safety Metrics Results. Table 4 shows the number of pedestrian phase truncations and the percentage value (e.g., the number of pedestrian phase truncations divided by the total number of active pedestrian phases) for each of the six EB scenarios examined. The data are provided for the $33 \mathrm{rd}$ Street IHGRC, the 35th Street IHGRC, and the 44th Street IHGRC. Tables 5 and 6 show the same information for the WB scenarios and both direction scenarios, respectively. It may be seen that the SP algorithm resulted in significant truncations of pedestrian signal-phase cutoffs in the range of 35 to 133 per hour for the baseline scenarios. When the TPS_DT algorithm was used, these were reduced 
TABLE 4: Pedestrian phase cutoffs for the scenarios with EB trains.

\begin{tabular}{|c|c|c|c|c|c|}
\hline Intersection & Scenario & $\begin{array}{l}\text { Pedestrian phase } \\
\text { truncations }\end{array}$ & $\begin{array}{c}\text { Active pedestrian } \\
\text { phases }\end{array}$ & $\begin{array}{l}\text { Percentage of pedestrian phase } \\
\text { truncations }(\%)\end{array}$ & $\begin{array}{c}\text { Percentage reduction } \\
(\%)\end{array}$ \\
\hline \multirow{6}{*}{$\begin{array}{l}\text { 33rd St } \\
\text { intersection }\end{array}$} & S-E-1 & 35 & 50 & 70.0 & \multirow{2}{*}{100.0} \\
\hline & $\mathrm{T}-\mathrm{E}-1$ & 0 & 50 & 0.0 & \\
\hline & S-E-3 & 88 & 150 & 58.7 & \multirow{2}{*}{98.9} \\
\hline & T-E-3 & 1 & 150 & 0.7 & \\
\hline & S-E-5 & 131 & 228 & 57.5 & \multirow{2}{*}{95.4} \\
\hline & T-E-5 & 6 & 229 & 2.6 & \\
\hline \multirow{6}{*}{$\begin{array}{l}\text { 35th St } \\
\text { intersection }\end{array}$} & S-E-1 & 27 & 50 & 54.0 & \multirow{2}{*}{100.0} \\
\hline & T-E-1 & 0 & 50 & 0.0 & \\
\hline & S-E-3 & 79 & 150 & 52.7 & \multirow{2}{*}{97.5} \\
\hline & T-E-3 & 2 & 150 & 1.3 & \\
\hline & S-E-5 & 118 & 231 & 51.1 & \multirow[b]{2}{*}{88.1} \\
\hline & T-E-5 & 14 & 231 & 6.1 & \\
\hline \multirow{6}{*}{$\begin{array}{l}\text { 44th St } \\
\text { intersection }\end{array}$} & S-E-1 & 28 & 50 & 56.0 & \multirow{2}{*}{100.0} \\
\hline & T-E-1 & 0 & 50 & 0.0 & \\
\hline & S-E-3 & 81 & 143 & 56.6 & \multirow{2}{*}{97.5} \\
\hline & T-E-3 & 0 & 143 & 0.0 & \\
\hline & S-E-5 & 133 & 238 & 55.6 & \multirow{2}{*}{88.1} \\
\hline & T-E-5 & 15 & 238 & 6.3 & \\
\hline
\end{tabular}

TABLe 5: Pedestrian phase cutoffs for the scenarios with WB trains.

\begin{tabular}{|c|c|c|c|c|c|}
\hline Intersection & Scenario & $\begin{array}{l}\text { Pedestrian phase } \\
\text { truncations }\end{array}$ & $\begin{array}{l}\text { Active pedestrian } \\
\text { phases }\end{array}$ & $\begin{array}{l}\text { Percentage of pedestrian phase } \\
\text { truncations }(\%)\end{array}$ & $\begin{array}{c}\text { Percentage reduction } \\
(\%)\end{array}$ \\
\hline \multirow{6}{*}{$\begin{array}{l}\text { 33rd St } \\
\text { intersection }\end{array}$} & S-W-1 & 26 & 50 & 52.0 & \multirow{2}{*}{100.0} \\
\hline & $\mathrm{T}-\mathrm{W}-1$ & 0 & 50 & 0.0 & \\
\hline & S-W-3 & 98 & 150 & 65.3 & \multirow{2}{*}{99.0} \\
\hline & T-W-3 & 1 & 150 & 0.7 & \\
\hline & S-W-5 & 131 & 231 & 56.7 & \multirow{2}{*}{88.5} \\
\hline & $\mathrm{T}-\mathrm{W}-5$ & 15 & 231 & 6.5 & \\
\hline \multirow{6}{*}{$\begin{array}{l}\text { 35th St } \\
\text { intersection }\end{array}$} & S-W-1 & 24 & 50 & 48.0 & \multirow{2}{*}{100.0} \\
\hline & $\mathrm{T}-\mathrm{W}-1$ & 0 & 50 & 0.0 & \\
\hline & S-W-3 & 75 & 150 & 50.0 & \multirow{2}{*}{84.0} \\
\hline & T-W-3 & 12 & 150 & 8.0 & \\
\hline & $S-W-5$ & 108 & 232 & 46.6 & \multirow[b]{2}{*}{90.7} \\
\hline & $\mathrm{T}-\mathrm{W}-5$ & 10 & 232 & 4.3 & \\
\hline \multirow{6}{*}{$\begin{array}{l}\text { 44th St } \\
\text { intersection }\end{array}$} & S-W-1 & 30 & 50 & 60.0 & \multirow{2}{*}{100.0} \\
\hline & $\mathrm{T}-\mathrm{W}-1$ & 0 & 50 & 0.0 & \\
\hline & S-W-3 & 82 & 150 & 54.7 & \multirow{2}{*}{100.0} \\
\hline & T-W-3 & 0 & 150 & 0.0 & \\
\hline & S-W-5 & 145 & 246 & 58.9 & \multirow{2}{*}{93.8} \\
\hline & T-W-5 & 9 & 246 & 3.7 & \\
\hline
\end{tabular}

considerably and were in the range of 0 to 63 . Compared to the baseline scenarios, the average reduction of pedestrian phase truncation was $92 \%$ and the reduction range was between 59 and 100 percent.

In the scenarios with one train (scenario T-E-1 and scenario $\mathrm{T}-\mathrm{W}-1$ ), the pedestrian truncation issue was eliminated because the TPS_DT module were initiated for every preemption event in these scenarios. For the scenarios that had more than one train during the simulation, it was observed that if more than one train passed the same HRGC and the TPS_DT module had already been implemented for an earlier train, the TPS-DT could not be initiated again while the earlier train was still in the SP phase due to the programming limitations of the VAP module in VISSIM [34]. For those trains approaching the HRGCs without the TPS_DT being activated, only the SP was initiated. In these situations, some of the pedestrian phases ended up being truncated. It can be observed that, with TPS_DT, all the pedestrian truncations occurred at those scenarios with medium or high train volumes (i.e., $3 \mathrm{veh} / \mathrm{h}$ and $5 \mathrm{veh} / \mathrm{h}$ ). However, these scenarios represented only 8 percent of observed train events based on the preliminary study results in Table 1. This indicates that TPS_DT may eliminate pedestrian truncations in most train events if it is implemented in the field.

4.6.2. Performance Metric Results. Table 7 compares the average MOE values for the optimization scenarios and the respective baseline scenarios. It can be seen in Tables 7(a) and 7(b) that all optimization scenarios using the TPS_DT algorithm experienced a reduction in delay at the three target 
TABLE 6: Pedestrian phase cutoffs for the scenarios with trains in both directions.

\begin{tabular}{|c|c|c|c|c|c|}
\hline Intersection & Scenario & $\begin{array}{l}\text { Pedestrian phase } \\
\text { truncations }\end{array}$ & $\begin{array}{c}\text { Active pedestrian } \\
\text { phases }\end{array}$ & $\begin{array}{l}\text { Percentage of pedestrian phase } \\
\text { truncations }(\%)\end{array}$ & $\begin{array}{c}\text { Percentage reduction } \\
(\%)\end{array}$ \\
\hline \multirow{6}{*}{$\begin{array}{l}\text { 33rd St } \\
\text { intersection }\end{array}$} & S-E-1 & 26 & 52 & 50.0 & \multirow{2}{*}{100.0} \\
\hline & $\mathrm{T}-\mathrm{E}-1$ & 0 & 52 & 0.0 & \\
\hline & S-E-3 & 80 & 157 & 51.0 & \multirow[b]{2}{*}{98.8} \\
\hline & T-E-3 & 1 & 157 & 0.6 & \\
\hline & S-E-5 & 128 & 222 & 57.7 & \multirow{2}{*}{88.8} \\
\hline & T-E-5 & 14 & 216 & 6.5 & \\
\hline \multirow{6}{*}{$\begin{array}{l}\text { 35th St } \\
\text { intersection }\end{array}$} & S-E-1 & 32 & 51 & 62.7 & \multirow{2}{*}{100.0} \\
\hline & $\mathrm{T}-\mathrm{E}-1$ & 0 & 51 & 0.0 & \\
\hline & S-E-3 & 79 & 154 & 51.3 & \multirow{2}{*}{81.0} \\
\hline & T-E-3 & 15 & 154 & 9.7 & \\
\hline & S-E-5 & 109 & 203 & 53.7 & \multirow{2}{*}{90.8} \\
\hline & T-E-5 & 10 & 203 & 4.9 & \\
\hline \multirow{6}{*}{$\begin{array}{l}\text { 44th St } \\
\text { intersection }\end{array}$} & S-E-1 & 45 & 69 & 65.2 & \multirow{2}{*}{69.8} \\
\hline & T-E-1 & 14 & 71 & 19.7 & \\
\hline & S-E-3 & 134 & 216 & 62.0 & \multirow{2}{*}{73.5} \\
\hline & T-E-3 & 36 & 219 & 16.4 & \\
\hline & S-E-5 & 152 & 289 & 52.6 & \multirow{2}{*}{58.6} \\
\hline & T-E-5 & 63 & 289 & 21.8 & \\
\hline
\end{tabular}

TABLE 7: Comparison of multiple run results between optimization and baseline scenarios.

\begin{tabular}{|c|c|c|c|c|c|c|}
\hline $\begin{array}{l}\text { Number of } \\
\text { trains }\end{array}$ & $\begin{array}{l}\text { Simulation } \\
\text { scenarios }\end{array}$ & $\begin{array}{c}\text { (1) Average delay (s/ } \\
\text { veh): baseline scenarios }\end{array}$ & $\begin{array}{l}\text { (2) Average delay (s/veh): } \\
\text { optimization scenarios }\end{array}$ & $\begin{array}{c}(2)-(1) /(1) \\
\text { difference }(\%)\end{array}$ & $\mathrm{P}(T \leq t))$ & $\begin{array}{l}H_{0}^{*}:(1)=(2) \\
H_{1}:(1)>(2)\end{array}$ \\
\hline \multicolumn{7}{|c|}{ (a) Average delay of the target intersections } \\
\hline 1 train in $\mathrm{EB}$ & S-E-1 vs. T-E-1 & 60.27 & 48.30 & -19.9 & 0.00 & Reject $\mathrm{H}_{0}$ \\
\hline 3 trains in $\mathrm{EB}$ & S-E-3 vs. T-E-3 & 66.93 & 61.82 & -7.6 & 0.01 & Reject $\mathrm{H}_{0}$ \\
\hline 5 trains in $\mathrm{EB}$ & S-E-5 vs. T-E-5 & 89.96 & 76.48 & -15.0 & 0.00 & Reject $\mathrm{H}_{0}$ \\
\hline 1 train in $\mathrm{WB}$ & $\begin{array}{c}\text { S-W-1 vs. T- } \\
\text { W-1 }\end{array}$ & 62.73 & 51.86 & -17.3 & 0.00 & Reject $\mathrm{H}_{0}$ \\
\hline 3 trains in $\mathrm{WB}$ & $\begin{array}{c}\text { S-W-3 vs. T- } \\
\text { W-3 }\end{array}$ & 71.10 & 68.46 & -3.7 & 0.07 & Accept $\mathrm{H}_{0}$ \\
\hline 5 trains in $\mathrm{WB}$ & $\begin{array}{c}\text { S-W-5 vs. T- } \\
\text { W-5 }\end{array}$ & 96.91 & 83.50 & -13.8 & 0.00 & Reject $\mathrm{H}_{0}$ \\
\hline $\begin{array}{l}1 \text { train in } \mathrm{EB} \\
\& \mathrm{WB}\end{array}$ & S-B-1 vs. T-B-1 & 68.28 & 57.27 & -16.1 & 0.00 & Reject $\mathrm{H}_{0}$ \\
\hline $\begin{array}{l}3 \text { trains in } \mathrm{EB} \\
\& \mathrm{WB}\end{array}$ & S-B-3 vs. T-B-3 & 69.30 & 57.23 & -17.4 & 0.00 & Reject $\mathrm{H}_{0}$ \\
\hline $\begin{array}{l}5 \text { trains in } \mathrm{EB} \\
\& \mathrm{WB}\end{array}$ & S-B-5 vs. T-B-5 & 129.67 & 108.29 & -16.5 & 0.00 & Reject $\mathrm{H}_{0}$ \\
\hline Average & 79.46 & (b) & $\begin{array}{c}-14.3 \% \\
\text { Iverage corridor delay }\end{array}$ & & & \\
\hline 1 train in $\mathrm{EB}$ & S-E-1 vs. T-E-1 & 72.57 & 65.12 & -10.3 & 0.00 & Reject $\mathrm{H}_{0}$ \\
\hline 3 trains in $\mathrm{EB}$ & S-E-3 vs. T-E-3 & 77.27 & 73.60 & -4.8 & 0.00 & Reject $\mathrm{H}_{0}$ \\
\hline 5 trains in $\mathrm{EB}$ & S-E-5 vs. T-E-5 & 88.41 & 85.15 & -3.7 & 0.00 & Reject $\mathrm{H}_{0}$ \\
\hline 1 train in $\mathrm{WB}$ & $\begin{array}{c}\text { S-W-1 vs. T- } \\
\text { W-1 }\end{array}$ & 74.77 & 69.90 & -6.5 & 0.00 & Reject $\mathrm{H}_{0}$ \\
\hline 3 trains in $\mathrm{WB}$ & $\begin{array}{c}\text { S-W-3 vs. T- } \\
\text { W-3 }\end{array}$ & $77.95 \mathrm{~s}$ & 75.52 & -3.1 & 0.00 & Reject $\mathrm{H}_{0}$ \\
\hline 5 trains in $\mathrm{WB}$ & $\begin{array}{c}\text { S-W-5 vs. T- } \\
\text { W-5 }\end{array}$ & 91.46 & 84.59 & -7.5 & 0.00 & Reject $\mathrm{H}_{0}$ \\
\hline $\begin{array}{l}1 \text { train in } \mathrm{EB} \\
\& \mathrm{WB}\end{array}$ & S-B-1 vs. T-B-1 & 77.26 & 66.30 & -14.2 & 0.00 & Reject $\mathrm{H}_{0}$ \\
\hline $\begin{array}{l}3 \text { trains in } \mathrm{EB} \\
\& \mathrm{WB}\end{array}$ & S-B-3 vs. T-B-3 & 86.12 & 70.56 & -18.1 & 0.00 & Reject $\mathrm{H}_{0}$ \\
\hline $\begin{array}{l}5 \text { trains in } \mathrm{EB} \\
\& \mathrm{WB}\end{array}$ & S-B-5 vs. T-B-5 & 108.05 & 86.42 & -20.0 & 0.00 & Reject $\mathrm{H}_{0}$ \\
\hline Average & 83.76 & 75.24 & -10.2 & & & \\
\hline
\end{tabular}

${ }^{*}$ denotes reject $\mathrm{H}_{0}$ at the $5 \%$ significance level. 
intersections. On average, there is a $14.3 \%$ reduction in average delay of the target intersections. Moreover, the delay reduction of the target intersections was statistically significant at the $5 \%$ significance level in 8 out of the 9 optimization scenarios. The only exception is Scenario $1-\mathrm{W}-3$, where the improvement was not statistically significant at the $5 \%$ significance level.

At the corridor level, the optimized signal timing plans resulted in significant decreases of average delay in all 9 scenarios at a 95\% confidence level, as shown in Table 7(b). Over the 9 scenarios, there is a $10.2 \%$ improvement in average corridor delay. The average delay reduction for the three target intersections near HRGCs is higher than that for the whole corridor. It is hypothesized that this occurred because the signal timing settings of the other three intersections in the corridor (27th St and Cornhusker Hwy, 29th St and Cornhusker Hwy, and 48th St and Cornhusker Hwy) were not included in the optimization process $[33,37]$.

\section{Impact Analysis of Prediction Errors}

It should be noted that the maximum benefits for the proposed TPS_DT algorithm occurs when train speeds are constant, which means that the predicted train arrival times are essentially 100 percent accurate. With the recent advance of Positive Train Control, the authors believe these requirements will be readily available in the near future $[27,29,30]$. Therefore, in the above analysis, it was assumed that all trains traveled at constant speed throughout the network. The arrival time of a train at the HRGC was predicted as the quotient of the distance from the upstream detection location to the target HRGC and the train speed. This predicted arrival time is updated simply by counting down the predicted arrival time at the upstream location. In other words, there was no prediction error for train arrivals in the previous analysis.

In practice, however, train speeds are not constant and all train arrival predictions have some degree of error under the existing train detection systems, e.g., the CWT railroad detector or the Doppler radar detectors equipped at the upstream locations of the study corridor [26-28]. Therefore, the TPS_DT is designed to be compatible with the exiting train detection systems, as long as they can provide train arrival information with acceptable prediction accuracy. Out of these considerations, it is necessary to investigate the effects of prediction errors on safety and delay of the HRGC corridor. Consequently, a sensitivity analysis of the safety and delay metrics as a function of travel time prediction errors is conducted in this section.

Figure 7 shows the trajectories of a train for underpredicted (Case B) and overpredicted scenarios (Case A), respectively. The solid line indicates the actual train trajectory that arrives the same time as the predicted arrival time. The dashed line on the right of the solid line represents Case A, where the train arrives at the HRGC earlier than the predicted arrival time. In this situation, the SP will start earlier, and the
TPS_DT algorithm will be terminated earlier. If a pedestrian phase is active when the TPS_DT algorithm is being terminated, it will be truncated. Meanwhile, the dashed line on the left of the solid line represents Case B, where a train arrives later than the predicted arrival time. In this case, the SP will start later than it is expected. As a result, the current phase will remain green, or the track clearance phase will be initiated before the SP starts. This will result in extension of the current phase or a longer track clearance phase. However, this situation will not affect pedestrian safety.

To emulate the prediction errors, an error term " $\epsilon$," which is defined as the difference between the actual train arrival time and predicted train arrival time, was added to the estimated train arrival time in the TPS_DT logic, as shown in equations (11) and (12). By varying the value of this error term, the impact of prediction errors on the safety and delay of the study corridor can be evaluated:

$$
\begin{gathered}
O_{k_{-} \mathrm{EB}}^{l}=A_{k_{\mathrm{EB}}}^{l}-\varepsilon, \\
O_{k_{-} \mathrm{WB}}^{l}=A_{k_{\mathrm{WB}}}^{l}-\varepsilon,
\end{gathered}
$$

where $O_{k_{-} \mathrm{EB}}^{l}$ is the modified estimated EB train arrival time to the $l^{\text {th }}$ HRGC at the end of $k$ seconds after the train was detected by the advanced detector. This parameter is updated every $t$ seconds as the train approaches the crossing. $t=1$ in this paper; $O_{k_{-} \text {WB }}^{l}$ is the modified estimated WB train arrival time to the $l^{\text {th }}$ HRGC at the end of $k$ seconds after the train was detected by the advanced detector. This parameter is updated every $t$ seconds as the train approaches the crossing. $t=1$ in this paper; $A_{k_{-} \mathrm{EB}}^{l}$ is the actual EB train arrival time to the $l^{\text {th }}$ HRGC at the end of $k$ seconds after the train was detected by the advanced detector; $A_{k_{-} \mathrm{WB}}^{l}$ is the actual WB train arrival time to the $l^{\text {th }}$ HRGC at the end of $k$ seconds after the train was detected by the advanced detector; $\epsilon$ is the error term for estimated train arrival time.

In the previous sections, a one-hour simulation was conducted to evaluate the performance of TPS_DT during the AM peak period. In this section, the performance of TPS_DT for a scenario of real-time optimization was tested with prediction errors built in the train arrival prediction function of TPS_DT. In the simulation, two trains enter the simulation network from two ends of the railroad simultaneously at $600 \mathrm{~s}$, with a speed of $35 \mathrm{~km} / \mathrm{h}$ and would leave the simulation network at approximately $1200 \mathrm{~s}$. The simulation time was set to $1800 \mathrm{~s}$ to create a train event present in the simulation network almost entirely throughout the analysis period. Therefore, the analysis period was set between $600 \mathrm{~s}$ and 1500 s so that the traffic will recover after the train leaves the network [36]. Figure 8 illustrates the simulation period in relation to the analysis period in the simulation. Similar to the previous section, the SP and the current signal timing plan were implemented as the benchmark in the baseline scenario. In the optimization scenarios, TPS_DT was applied with the error term $\varepsilon$ for estimated train arrival time ranging from $-50 \mathrm{~s}$ to $50 \mathrm{~s}$ with an increment of $10 \mathrm{~s}$, and the signal timing was optimized using the GA method $[36,40]$. 


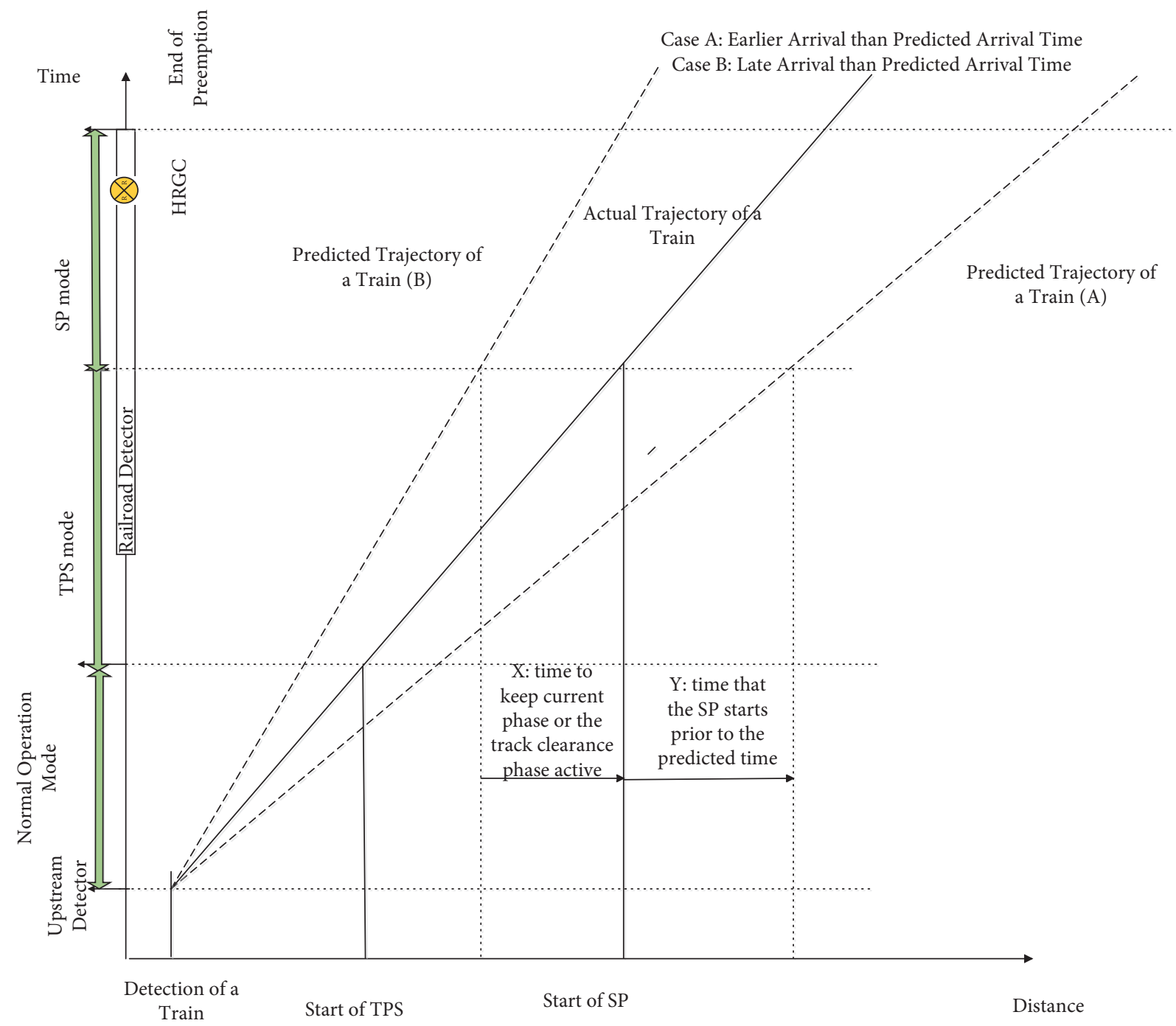

FIgURE 7: Train prediction errors and the resultant responses in the TPS_DT logic.

5.1. Safety Results. In the analysis, the percentage of pedestrian phase cutoffs, which is calculated as the quotient of the number of pedestrian cutoffs to the total number of active pedestrian phases during the simulation, was used as the safety metric. Figures 9-11 illustrate how the percentage of pedestrian phase cutoffs changes as a function of prediction error at the three target intersections. The dotted line in the figures represents the percentage of pedestrian phase cutoffs in the baseline scenario as a function of prediction errors, while the lines with markers represent the percentages of pedestrian phase cutoffs for the optimized scenario at the three target intersections. It can be seen in Figures 9 and 10 that negative prediction errors (earlier than predicted train arrival) resulted in more prediction phase truncations. This was particularly noticeable at the 35th St intersection, where the percentage of prediction cutoffs increases from 72 percent to 100 percent when the prediction error decreased from $-20 \mathrm{~s}$ to $-50 \mathrm{~s}$. At the $33 \mathrm{rd}$ Street intersection, the truncation rates range from 34 percent to 66 percent as the prediction error decreases from $-20 \mathrm{~s}$ to $-50 \mathrm{~s}$. Because there are no pedestrian phase cutoffs at the 44th Street intersection in the baseline scenario, the employment of TPS_DT did not lead to pedestrian phase cutoffs, regardless of the prediction error. Moreover, the percentage of pedestrian phase truncations remains zero when the pedestrian error is equal or above zero seconds. It is worth pointing out that when the prediction error is equal to $-10 \mathrm{~s}$, the percentage of pedestrian phase cutoffs is still 0 percent at the three target intersections. This is because, in the simulation, the pedestrian phases were not initiated within $10 \mathrm{~s}$ of the start of the SP algorithm (i.e., $\tau=10 \mathrm{~s}$ in L22). Thus, no pedestrian truncation will occur even if the railroad initiates the SP 10 seconds earlier than the prediction. It can be further hypothesized that if pedestrian phases are omitted $|\epsilon|$ seconds prior to the start of the SP, or even upon start of TPS_DT, the pedestrian phase truncations can be eliminated. The only concern is that pedestrians may end up violating the pedestrian phase red if the red phase duration is too long.

5.2. Delay Results. Figures 12 and 13 show the mean vehicular delay at the three target intersections and the corridor delay as a function of prediction error in $10 \mathrm{~s}$ increments, respectively. The delay in the baseline scenario 


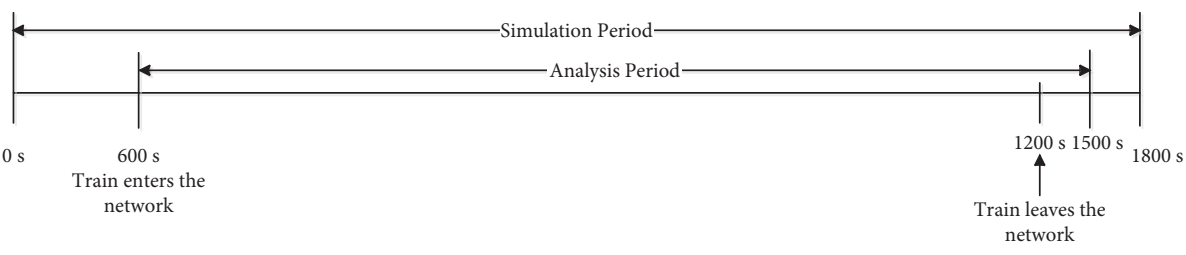

FIgURE 8: Time frame for analysis period during the sensitivity analysis.

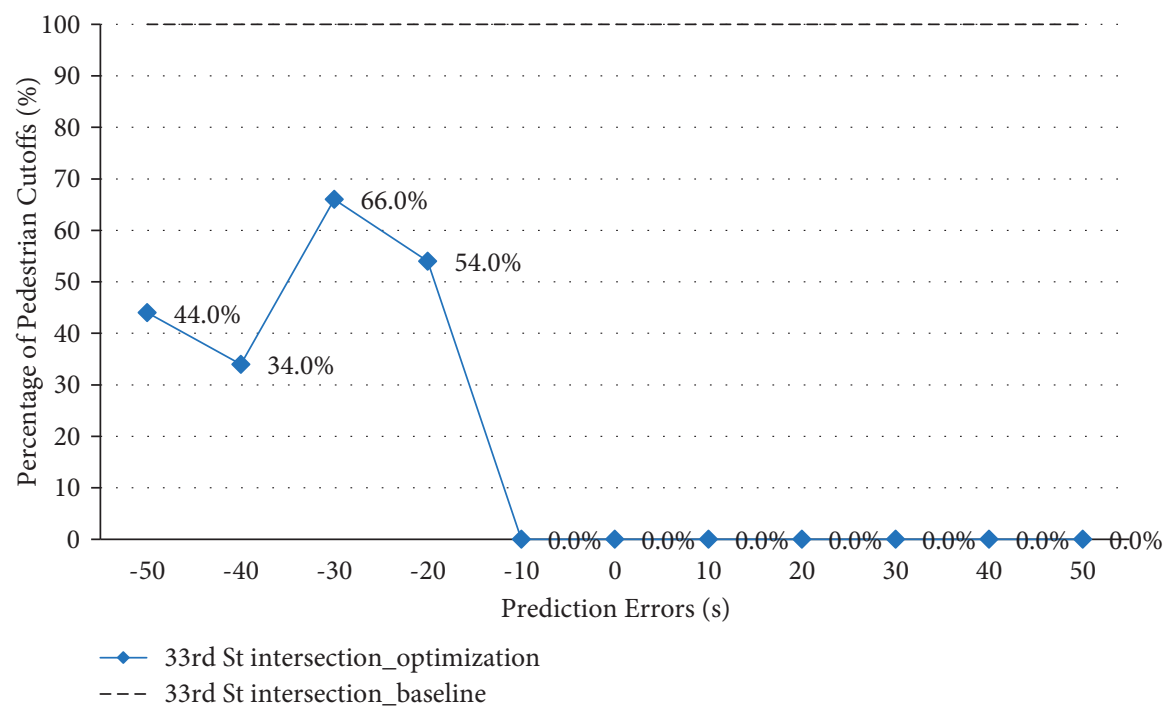

FIGURE 9: Percentages of pedestrian phase cutoffs in relation to prediction errors at 33rd Street intersection.

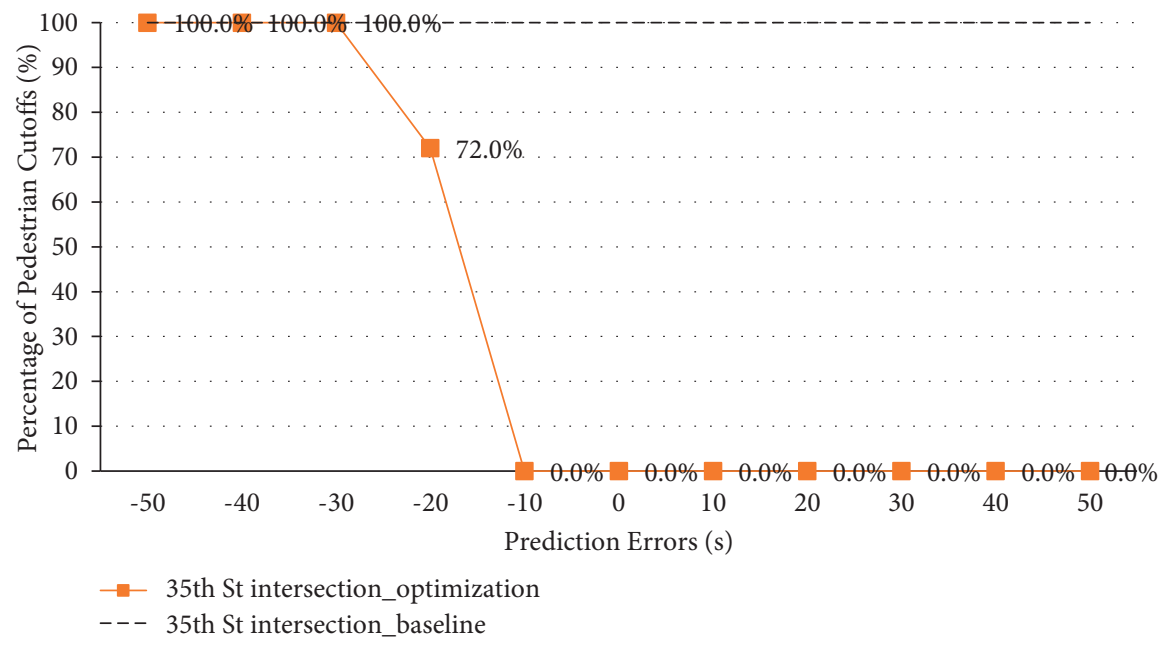

Figure 10: Percentages of pedestrian phase cutoffs in relation to prediction errors at 35th Street intersection.

with SP and 0 second of prediction error is shown as the benchmark (i.e., $0 \%$ in delay change) in these two tables. Compared to the baseline scenario, the optimized scenario with 0 prediction error has $11 \%$ less delay on average for the three target intersections and a reduction of delay by $5.8 \%$ at the corridor level. Furthermore, the average delay of the three target intersections in the optimization scenarios increases from $55.2 \mathrm{~s}$ to $61.7 \mathrm{~s}$, which is an 11.8 percent increase, as the prediction error increases from $0 \mathrm{~s}$ to $50 \mathrm{~s}$. At the corridor level, the average delay increases by 4.8 percent, as the prediction error increases from $0 \mathrm{~s}$ to $50 \mathrm{~s}$. These results would be expected due to the longer duration of the track clearance phase when the train arrived later than predicted.

When the prediction errors are negative (i.e., the train arrives earlier than predicted), the changes in average delay vary between $-14 \%$ and $10 \%$ at the three intersections and between $-6.6 \%$ and $7.3 \%$ at the corridor level. This indicates that the negative prediction errors could either reduce or increase the delay. 


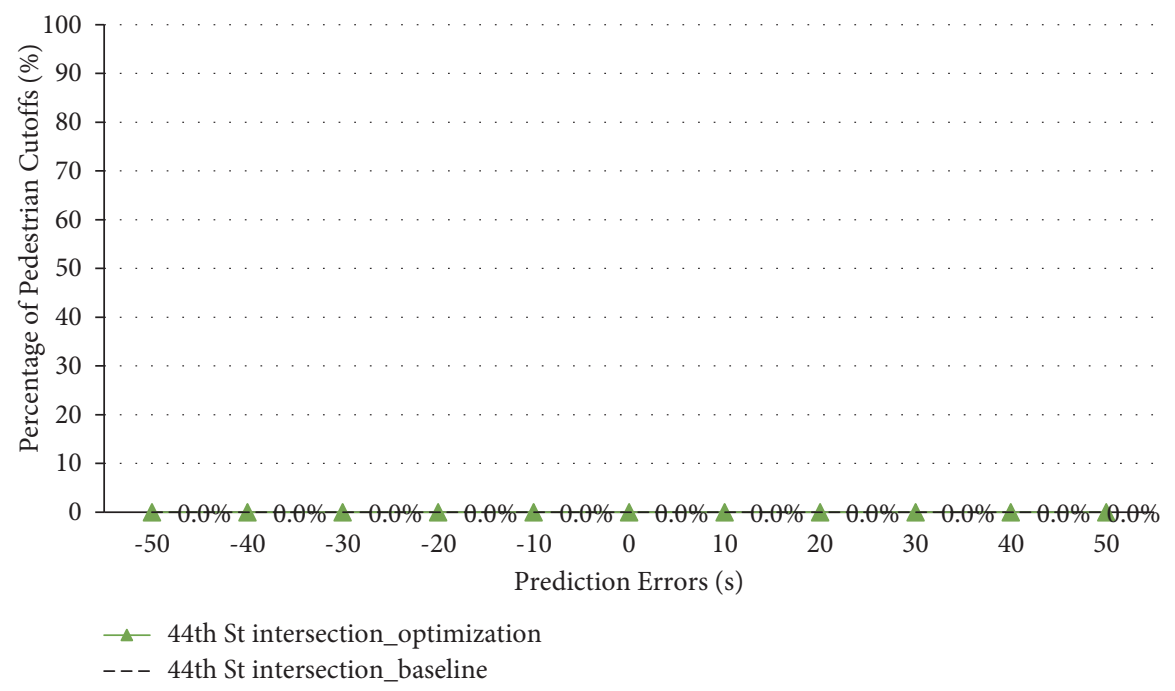

FIgUre 11: Percentages of pedestrian phase cutoffs in relation to prediction errors at 44th Street intersection.

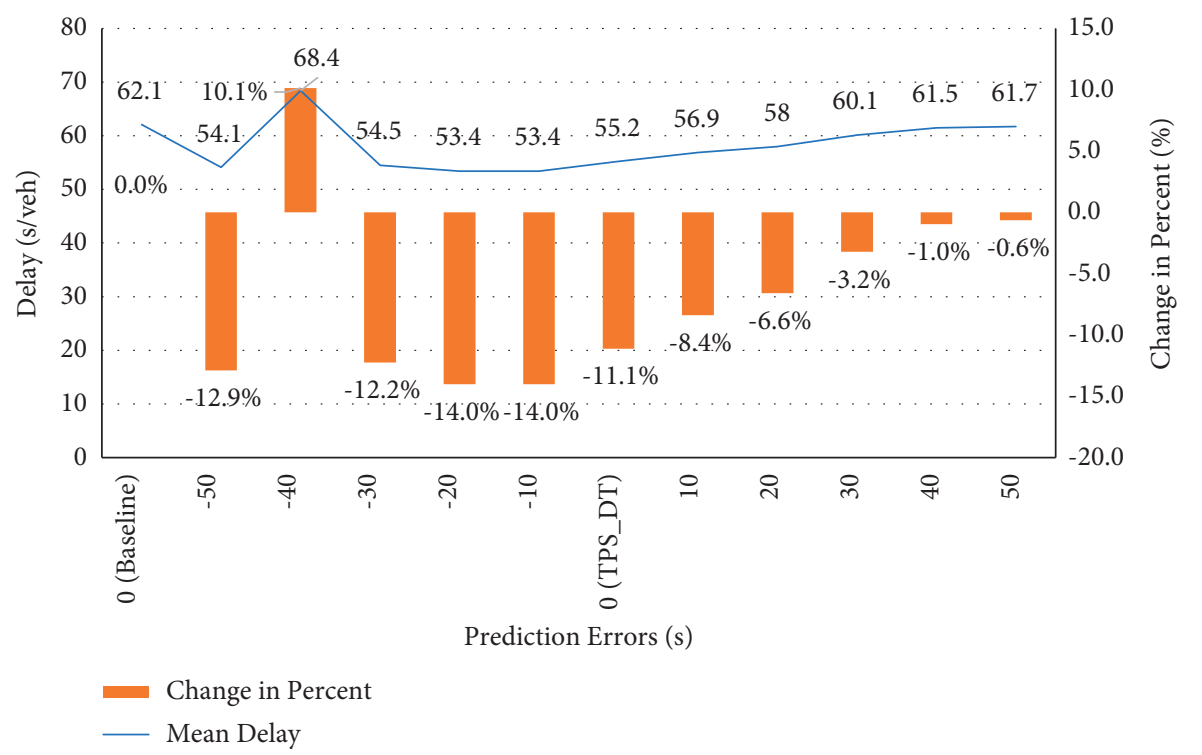

FIGURE 12: Average delay of the three target intersections near HRGCs versus prediction errors.

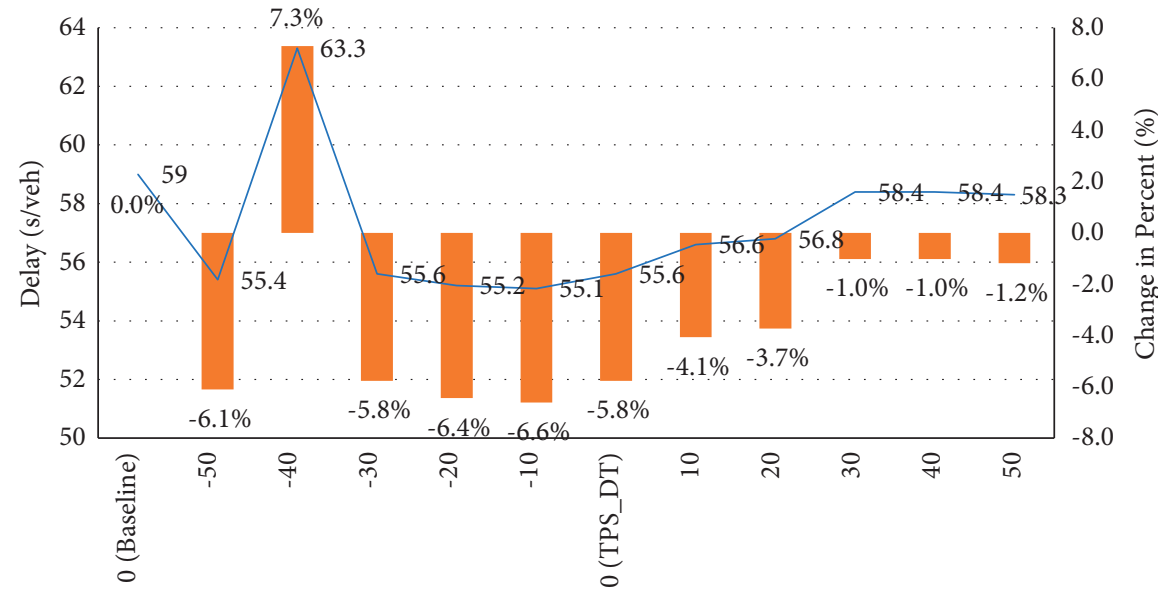

Prediction Errors (s)

Change in Percent

— Mean Delay

FIGURE 13: Average corridor delay versus prediction errors. 
However, as discussed in Figure 7, earlier arrival of the train may result in pedestrian phase cutoff. Therefore, negative prediction errors should be restrained or avoided in practice.

Based on the above analysis, it can be concluded that, for the study corridor, it is best to restrain the prediction errors within plus or minus $10 \mathrm{~s}$ because an absolute error of greater than $10 \mathrm{~s}$ would outweigh the benefits of TPS_DT in terms of both safety and delay. It is hypothesized that a PTC system or advanced train prediction algorithm is needed to achieve this level of accuracy [27, 29, 30].

\section{Concluding Remarks}

In this study, an advanced transition preemption strategy, entitled TPS_DT, was developed to improve safety and efficiency of highway corridors with multiple HRGCs and dual railroad tracks. Compared to the previous methodologies [8-10], the algorithm can handle not only a single train but also multiple trains traveling in the same or opposite directions. The objective of the algorithm is to improve safety of pedestrians and drivers while simultaneously improving efficiency.

A sensitivity analysis in the VISSIM simulation environment was conducted with different train departure and volume scenarios. The simulation results show that the TPS_DT algorithm can mitigate most of the pedestrian phase cutoffs at HRGCs. Furthermore, the TPS_DT can simultaneously reduce the average delay of the target intersections and the whole corridor, when working with an advanced signal timing optimization method, such as GA. These reductions were found to be statistically significant at the $95 \%$ level of significance.

Furthermore, a simulation analysis was conducted with regards to the impacts of train arrival prediction errors on safety and delay of the study corridor. Negative prediction errors caused 34 percent to 100 percent more pedestrian phase cutoffs due to earlier train arrivals than predicted. On the contrary, positive prediction errors resulted in an increase of delay both at the three target intersections and in the whole corridor due to longer track clearance time. The pedestrian phase truncations can be eliminated by prohibiting the pedestrian phases prior to the start of the SP or even upon start of TPS_DT. The increase of delay due to positive prediction errors can be mitigated or eliminated by increasing the accuracy of the prediction models. It is hypothesized that, with the advent of the positive train control (PTC), this level of accuracy will be obtained easily. In addition, with the implementation of the PTC, the possibility at implementing this type of algorithm on corridors with large traffic volumes and IHRGCs is possible because it will not involve a significant cost in infrastructure.

Note that there are no technical issues related to using PTC information in the proposed algorithm. However, the political issues will, in all likelihood, be difficult. Railway companies have historically resisted providing train arrival information to roadway transportation agencies beyond that which is required by law. It should be noted that the motivation behind the US federal law requiring PTC systems in the US was based on safety concerns at HRGCs. It is not hard to imagine a scenario where the safety of pedestrians and drivers at intersections near HRGCs would result in changes to federal law that would allow PTC information to be utilized by roadway authorities.

It is important to note that, in this paper, all the simulations that were analyzed used AM peak hour traffic volumes, predefined train volumes, and predefined departure times. Therefore, it is necessary to evaluate the safety and efficiency benefits of TPS_DT at other HRGC locations, under different traffic demand levels (e.g., PM peak hour traffic demand level or off-peak traffic demand level), train volumes, and train arrival/departure times. In addition, although simulation studies have shown that TPS_DT can improve safety and efficiency of the corridor, field studies will be necessary to confirm the results from the simulation study before the new algorithm should be considered for widespread implementation in the field.

\section{Data Availability}

The simulation data used to support the findings of this study are included within the article and in $[36,40]$.

\section{Conflicts of Interest}

The authors declare that they have no conflicts of interest.

\section{Acknowledgments}

The authors would like to thank the City of Lincoln for assisting with the data collection. The authors gratefully acknowledge financial support from the United States Department of Transportation through the University Transportation Center for Railway Safety. The contents of this paper reflect the views of the authors, who are responsible for the facts and accuracy of the information presented herein and are not necessarily representative of the state of Nebraska, the city of Lincoln, or the United States Department of Transportation.

\section{References}

[1] U.S. Department of Transportation, Railroad-highway Grade Crossing Handbook, U.S. Department, Washington, DC, USA, 2nd edition, 2007.

[2] T. Urbanik and A. Tanaka, Trafc Signal Preemption at Intersections Near Highway-Rail Grade Crossings: NCHRP Synthesis 507Transportation Research Broad, Washington, DC, USA, 2017.

[3] S. Venglar, "High-Speed Rail IDEA Program Advanced Intersection Controller Response to Railroad Preemption: Final Report for High-Speed Rail IDEA Project HSR-16," 2000, http://www.nationalacademies.org/trb/idea.

[4] H. W. Korve, Trafc Signal Operations Near Highway-railroad Grade Crossings: NCHRP Synthesis 271Transportation Research Board, Washington, DC, USA, 1999.

[5] L. Zhang, Optimizing trafc network signals around railroad crossings, Ph.D. thesis, Virginia Polytechnic Institute and State University, Blacksburg, USA, 2000. 
[6] P. Venglar, S. M. Venglar, S. R. Jacobson, S. R. Sunkari, E. J. Roelof, and T. Urbanik, "Guide for traffic signal preemption near railroad grade crossing," Technical Report FHWA/TX-01/1439-9, Texas Transportation Institute, College Station, TX, USA, 2000.

[7] R. J. Engelbrecht, "The effect of variation in railroad warning time on traffic signal preemption," in Proceedings of the Presented at the Sixth International Symposium on RailroadHighway Grade Crossing Research and Safety, Knoxville, TN, USA, October 2000.

[8] H. Cho, Preemption Strategy for intersections near highwayrailroad crossings, Ph.D. thesis, Texas AM University, College Station, Texas, USA, 2003.

[9] S. Venglar, "Advanced Intersection Controller Response to Railroad Preemption,” IDEA Program Final Report HSR-16, Transportation Research Board, Washington, D.C., USA, 2000.

[10] H. Cho and L. R. Rilett, "Improved transition preemption strategy for signalized intersections near at-grade railway grade crossing," Journal of Transportation Engineering, vol. 133, no. 8, pp. 443-454, 2007.

[11] J. R. Yohe and T. Urbanik, "Advance Preempt with Gatedown Confirmation Solution for Preempt Trap," Transportation Research Record, vol. 2035, no. 2035, pp. 40-49, 2007.

[12] R. N. Penabaena, V. Cantillo, J. L. Moura, and A. Ibeas, "Design and evaluation of a mathematical optimization model for traffic signal plan transition based on social cost function," Journal of Advanced Transportation, vol. 2017, Article ID 1943846, 12 pages, 2017.

[13] T. M. Brennan, C. M. Day, J. R. Sturdevant, E. M. Raamot, and D. M. Bullock, "Track Clearance Performance Measures for Railroad-Preempted Intersections," Transportation Research Record, vol. 2192, no. 1, 2010.

[14] S. Humagain, R. Sinha, E. Lai, and P. Ranjitkar, "A systematic review of route optimisation and pre-emption methods for emergency vehicles," Transport Reviews, vol. 40, no. 1, 2020.

[15] T. M. Brennan, J. R. Sturdevant, and D. M. Bullock, "Applied high resolution traffic controller data outcome based performance measures with gate-down confirmation circuit," in Proceedings of the ASME/IEEE Joint Rail Conference, pp. 431-437, Urbana, IL, USA, October 2010.

[16] X. Sun, T. Urbanik, S. Skehan, and M. Ablett, "Improved highway-railway interface for the preempt trap," Transportation Research Record, vol. 2080, no. 1, pp. 1-7, 2008.

[17] H. Cho, L. R. Rilett, and D. Park, "Analysis of performance of transitional preemption strategy for traffic signal near atgrade railway grade crossing," KSCE Journal of Civil Engineering, vol. 15, no. 3, pp. 569-579, 2011.

[18] T. Kim, A. Hobeika, and M. Abbas, "Genetic algorithm based stochastic optimization for preempted signals at highway railroad grade crossing," https://trid.trb.org/view/1264712 Report No. VT-2012-08, Mid-Atlantic Universities Transportation Center, Virginia Polytechnic Institute and State University, Blacksburg,VA, USA, 2013, https://trid.trb.org/ view/1264712 Report No. VT-2012-08.

[19] P. Lin, Z. Wang, Q. Wang, and R. Guo, "Coordinated prepreemption of traffic signals to enhance railroad grade crossing safety in urban areas and estimation of train impacts to arterial travel time delay," National Center for Transit Research, FDOT BDK85 977-44, 2014.
[20] X. Chen, Y. Xiao, M. Hadi, M. Ackert, and P. Lin, “Assessment of pre-preemption strategy of traffic signals near railroad grade crossing utilizing simulation analysis," in Proceedings of the 93rd Annual Meeting of the Transportation Research Board, Washington, DC, USA, January 2014.

[21] J. So, J. Kang, S. Park, I. Park, and J. Lee, "Automated emergency vehicle control strategy based on automated driving controls," Journal of Advanced Transportation, vol. 2020, Article ID 3867921, 11 pages, 2020.

[22] X. Qin and A. M. Khan, "Control strategies of traffic signal timing transition for emergency vehicle preemption," Transportation Research Part C: Emerging Technologies, vol. 25, pp. 1-17, 2012.

[23] H. Mu, Y. Song, and L. Liu, "Route-based signal preemption control of emergency vehicle," Journal of Control Science and Engineering, vol. 2018, Article ID 1024382, 11 pages, 2018.

[24] H. Mu, L. Liu, and X. Li, "Signal preemption control of emergency vehicles based on timed colored Petri Nets," Discrete Dynamics in Nature and Society, vol. 2018, Article ID 7095485, 12 pages, 2018.

[25] H. Mu, L. Liu, Y. Song, and N. Wang, "Control strategy of signal transition after emergency vehicle signal preemption," Discrete Dynamics in Nature and Society, vol. 2020, Article ID 1382415, 11 pages, 2020.

[26] Y. Chen and L. R. Rilett, "A train data collection and arrival time prediction system for highway-rail grade crossings," Transportation Research Record, vol. 2708, pp. 96-104, 2017.

[27] D. B. Work, W. Barbour, and R. Wang, "Improving railroad grade crossing safety: accurate prediction of train arrival times for emergency response management and driver decision support," http://hdl.handle.net/11299/202365 Center for Transportation Studies Research Report CTS 19-03, University of Minnesota, Minneapolis, MN, USA, 2019, http:// hdl.handle.net/11299/202365 Center for Transportation Studies Research Report CTS 19-03.

[28] H. Cho and L. R. Rilett, "Forecasting train travel time at Atgrade Crossings," Transportation Research Record, vol. 1844, pp. 94-102, 2003.

[29] Federal Railroad Administration, "Intelligent transportation system/positive train control at highway-rail intersections," Research Results Report, RR 07-20, U.S. DOT and FRA Office of Research and Development, Washington, DC, USA, 2007.

[30] A. Khattak and M. Lee, "Highway-rail crossing safety improvements by diverting motorist to alternate routes," https:// www.utrgv.edu/railwaysafety/research/operations/highwayrail-crossing-safety-diverting-motorists/index.htm University Transportation Center for Railway Safety Repearch Report, Report No. 26-1121-0018-007, University of NebraskaLincoln, Lincoln, NE, USA, 2018, https://www.utrgv.edu/ railwaysafety/research/operations/highway-rail-crossingsafety-diverting-motorists/index.htm University Transportation Center for Railway Safety Repearch Report, Report No. 26-1121-0018-007.

[31] “Average daily traffic volume," City of Lincoln, Lincoln, NE, USA, 2020, https://lincoln.ne.gov/city/ltu/engine/traffic/adtv/ pdf/2015-downtown.pdf.

[32] E. G. Jones, A. H. Khattak, and L. R. Rilett, "The university Nebraska-lincoln's highway rail grade crossing test bed system," in Proceedings Of the 88th Annual Meeting Of the Transportation Research Board, Washington, DC, USA, January 2009. 
[33] Federal Railroad Administration, Web Based Prediction System (WBAPS), 2021, https://railroads.dot.gov/highway-rail-crossingand-trespasser-programs/crossing-inventory/web-based-accidentprediction.

[34] "VISSIM user's manual, ," PTV Planning Transport Verkehr AG, Karlsruhe, Germany, 2011.

[35] D. E. Goldberg, Genetic Algorithms in Search, Optimization, and Machine Learning, Addison-Wesley Publishing Co., Inc, Reading, MA, USA, 1989.

[36] Y. F. Chen, An adaptive corridor-wide signal timing optimization methodology for traffic networks with multiple highwayrail grade crossings, Ph.D. thesis, Department of Civil Engineering, University of Nebraska-Lincoln, Lincoln, NE, USA, 2015.

[37] Z. Wu, "Evaluating the impact of highway-railway grade crossings on travel time reliability on a highway network level," Transportation Research Record, vol. 2672, pp. 1-11, 2018.

[38] Z. Wu, Measuring reliability in dynamic and stochastic transportation networks, Ph.D. thesis, University of NebraskaLincoln, Lincoln, USA, 2015.

[39] A. Justice, Quantifying uncertainties in synthetic origin-destination trip matrix estimates, Ph.D. thesis, University of Nebraska-Lincoln, Lincoln, USA, 2009.

[40] Y. F. Chen and L. R. Rilett, "Signal timing optimization for corridors with multiple highway-rail grade crossings using genetic algorithm," Journal of Advanced Transportation, vol. 2018, Article ID 9610430, 14 pages, 2018.

[41] NEMA Standards Publication, Traffic Controller Assemblies with NTCIP Requirements TS2-2003, National Electronical Manufacturers Association, VA, USA, 2012. 